\title{
الثهادة الأدبية وبناء صورة الذات الساردات السعوديات نموذجا
} د. عبد الله بن حمود الفوزان

قسم اللغة العربية وآدابها بجامعة القصيم. لقون.

مستخلص. يعد السرد النسوي السعودي علامة فارقة في تاريخ السرد العببي لقدرته في السنوات الأخيرة أن يكون محط أنظار المهتمين من نقاد ودور نشر ومترجمين. وقد ناقثت الدراسة طبيعة هذا السرد النسوي السعودي من منظور الثهادات الأدبية للساردات السعوديات التي حتما تعد نافذة معتبرة من نوافذ آليات كثف لفف

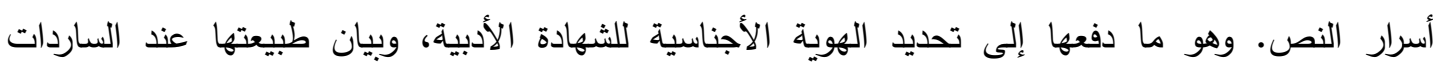
السعوديات. ثم بينت الدراسة الكيفية التي تعمل الثهادة الأدبية عبرها على بناء صورة الذات وعلاقة ذلك

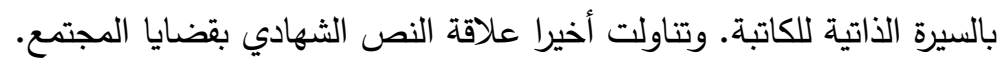

التي يكتبها المبدع حول عروشه الإبداعية، ورصده لمعانات الشعوب ومِحَنها، متجليا بسياق الحربين

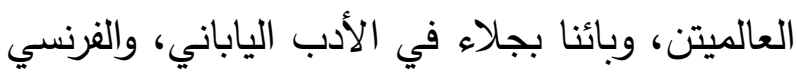

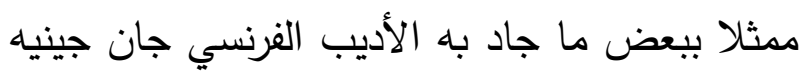

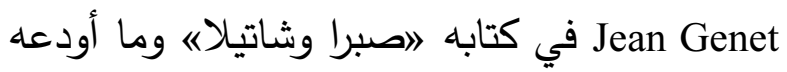
الأديب الأسباني خوان غويتيسولو Juan Goytisolo
تمهيد)

كعب عال واستلطاف جلي يحظى به النثر الأدبي في عصره هذا، روافده شتى وأحدها الشهادة الأدبية

Qassim University (') شكر وتقدير لجامعة القصيم (') ممثلة بعمادة البحث العلمي على دعمها هذا البحث.

Thanks to Qassim University for supporting this research. 
وتُجلّي ظهوره للمتلقي. أما المحور الثاني: فيرصد الذات إبّان تفاعلها مع قضايا المجتمع وتكثَّفها ودورها أمام تلك القضايا، وكلا المحورين يعملان على قراءة خاصة موجهة للنص الأدبي. ويتمظهر السرد النسوي السعودي كعلامة بائنة في مسيرة السرد العربي الحديث لتحليقه في السنوات

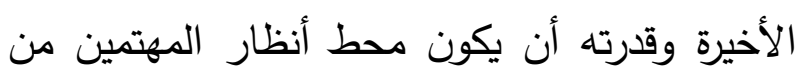

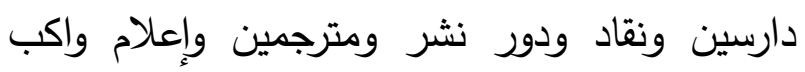

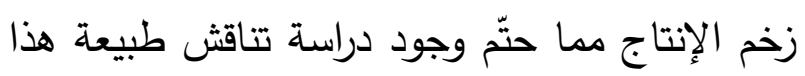
السرد النسوي السعودي من منظور الثهادات الأدبية

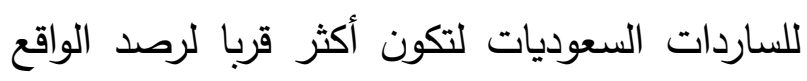
من مؤمليه، محاولة هذه الدراسة تقريب الإجابة عن

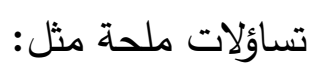
ما طبيعة الثهادة الأدبية التي تكتبها الساردات

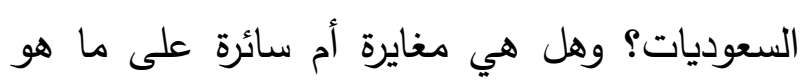
سائد من شهادات الكاتبات في بلدان أخرى؟

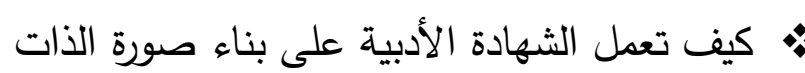
وما علاقة ذلك بالسيرة الذاتية للكاتبة؟ وهل يمكن القول بأنها نوع أدبي له خصائصه أم أنها واقعة في

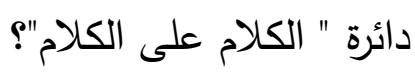
* كيف رصدت الساردات السعوديات علاقة النص بقضايا المجتمع على مستوى الشهادة الأدبية؟ منهجية البحث: يفترض البحث أن الشهادة الأدبية تمثل أهم ركيزة

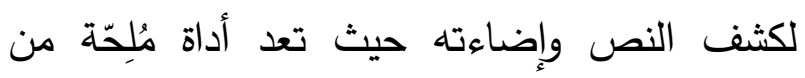

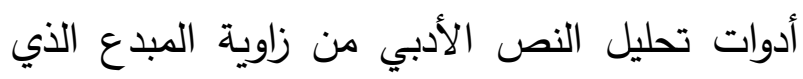

عن سراييفو، وما سطّره الأدب الفلسطيني عن أدب

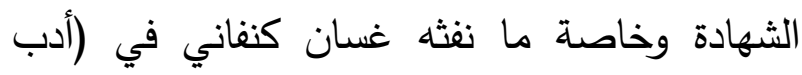
الثهادة) من متعة فنية عالية ساقته وسوقته عالميا، حيث كان شاهد فقدان لا شاهد عيان. وكذلك ما فاء به الأدب الأفريقي حول الشهادة كحرارة (الأشياء

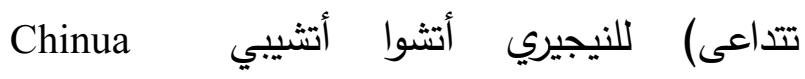
Chinụalumọgụ Achebe سوينكا Wole Soyinka في (مذكرات سجين). و (يوميات) للكاتب الجزائري مولود فرعون. وشهادات سمر يزبك السورية في كتابها (تقاطع نيران). ومن الأردن شهادة تيسير سبول في (أنت منذ اليوم) وشهادة غالب هلسا في (الكواليس والأحلام في تئي

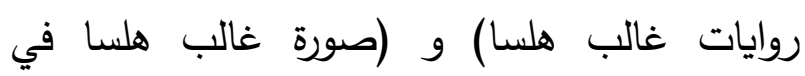
رواياته) وكذلك مؤنس الرزاز في (حين تختفي الرواية ويحضر البطل، ليلة البطل). هذا الحضور

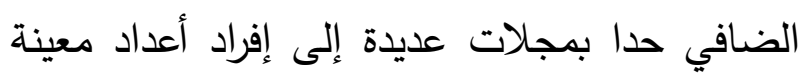

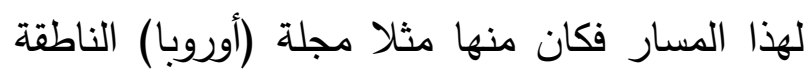
بالفرنسية التي أصدرت عددا مزدوجا ل (الثهادة في

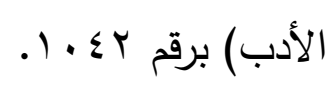
ومما سلف يتأكد البوح بأنه وإن كانت الثهادات

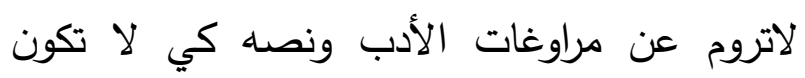

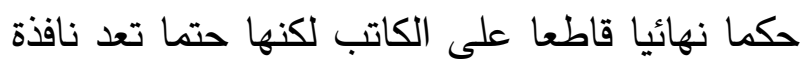
معتبرة من نوافذ آليات كثف أسرار النص. وتتأتى مكامنها وتتكثف عبر رصد محاور عدة: يمثل بناء الذات محورها الأول: إذ يعمد المبدع ملاطفة حروفه من أجل خلق صورة نموذجية تمثله أثناء العمل 
أن يكون مسموعا ومجديا ومشتركا"()). وبالتالي الخلوص بأن بناء صورة الذات في الشهادة الأدبية يتشكل من الذات المنتجة والذات المستهلكة، وأن الجدل بينهما هو جوهر التجربة أو ربما أداة الوعي، ودور الشهادة الأدبية يكمن في القرب من إدراك المغزى وما يترتب على أفق التوقع أو الترقب أو الانتظار بين الذاتين المنتجة والمستهلكة، وهو ما حدا بالدراسة أن تركز على البعد السوسيولوجي في تلقي الثهادة الأدبية(r). ويبقى التساؤل مفتوحا: هل يمكن أن تكون للشهادة الأدبية خصائصها النوعية التي تجعل منها نوعا أدبيا خالصا؟ أم تظل الثهادة الأدبية لونا من ألوان تفسير النص الأدبي؟ الثهادة الأدبية وقضية النوع الأدبي: يتجلى للراني في نقدنا العربي القديم أن مقولات المبدع حول نصه كانت هي فاصلة القول في دلالات النص فقد ظلت مقولات الشعراء حول شعرهم تتصدر أحكام المشهد النقدي في خطوه الأول، ثم مع ظهور القارئ الفاحص في النقد المعاصر، واتساع الاهتمام به في المناهج الأدبية، تفلتت تلك السلطة الأحادية للمبدع وأُشرع السجال بين الناقد والقائل في أحقية تفسير النص. وربما انعكس مردود النص الإيجابي على القارئ أكثر منه على المنتج

( أ) الثهادة الأدبية والتجربة الإبداعية:عبد الرحمن مجيد الربيعي

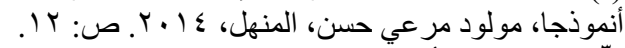

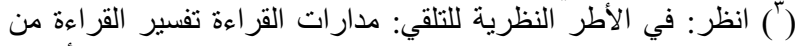

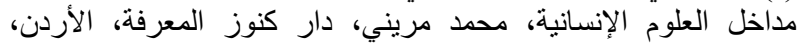

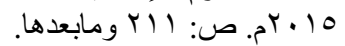

يبوح لقارئه، إذ تتمظهر صورة الذات بشكل جلي في الثهادة الأدبية، وتنأى المثاليات لتتجلى لتورئ حقائق

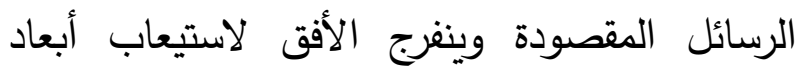
النص ومغازيها. وهذا داع مُلح وبُعد مقصود دَفَعَا

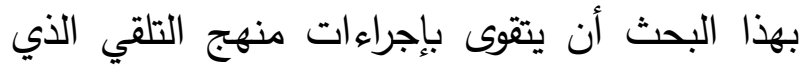

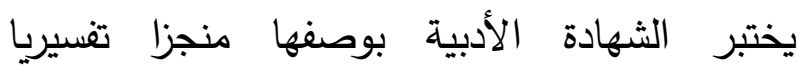

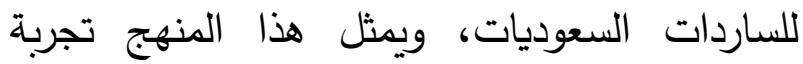
ووعيًا بأنّ نصوصهن قد تحتاج إلى ما يعضدها من آليات تعمل على تلقيها بشكل صحيح، فلا يختلط

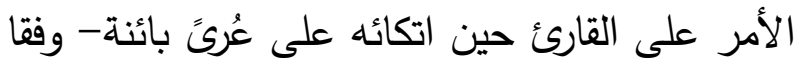
لتصورات الكاتبات - بين ما هو ذاتي آني خاص، لهاص وما هو تخييلي حالم يحاول رسم صورة للمجتمع عن طريق مجموعة من الشخصيات والأدوات المعينة. وهو ما يعني أنّ التلقي الواعي لنصوصهن الإبداعية

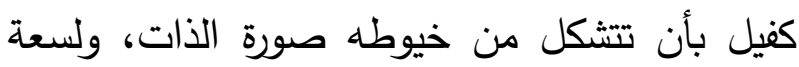
الثهادة فإنه يمكن أن يكون العكس صحيحا أيضا، وهو ما يستدعي بالضرورة معرفة كيف تلقى المجتمع القضايا المطروحة في النص الإبداعي، وما الدور الذي يمكن أن تقوم به الثهادة الأدبية بوصفها نشاطا تفسيريا للنص الإبداعي. يؤكد الربيعي هذا

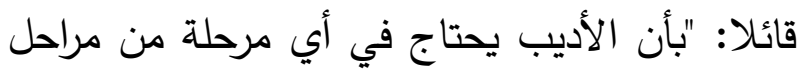

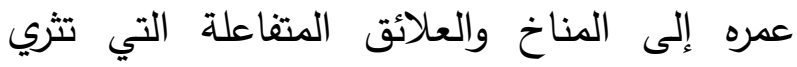
الحوار وتبلور التجارب وتوصل الغايات، إذ إن الكتابة رغم كونها عملا فرديا بحتا إلا أنها وبصورتها الأشمل فضاء اجتماعي وصوت يعمل مطلقه على 
نص نثري كتبه مبدع يمتلك مهارة الحكي، وما يلازم

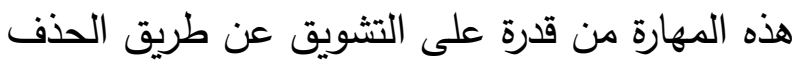

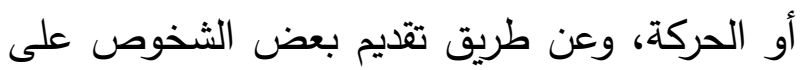
مسرح الشهادة أو تأخيرها، وعن طريق إبراز المكان البطل أو الحدث الثخصية أو غير ذلك حيث يون يورد السيرة الذاتية، ويمرر اليوميات، ربما طغى أحيانا

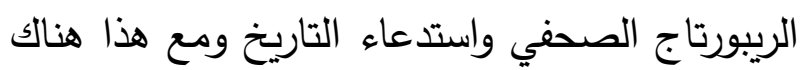
بروز لعلاقة هذا النوع بالواقع وكتابة التاريخ. إذ " تمثل الشهادة الأدبية التي يقدم فيها الأديب سردا سيريا في طبيعة وظروف وحالات منتجه الإبداعي"("). مما أدى إلى ظهور اختلاف مقبول بين تصورات الباحثين، وفقاً لمنظور تلقيهم للنماذج الإدي السائدة من الشهادات الأدبية. وهو ما تحاول هذه الدراسة استجلاءه والغور فيه في الفقرات القادمة.

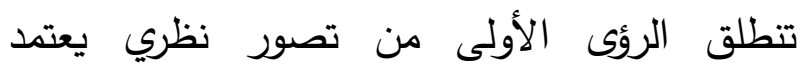
التجنيس الأدبي، وتمييز الأشكال الأدبية ضروئ لفوري علمية وقيمة منهجية ملحة تعتمد في هذا على نهج

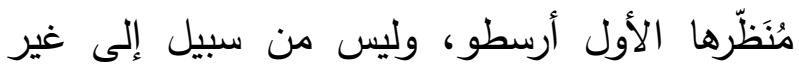

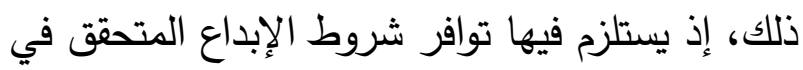
كتابة نصوص تجمعها عدد من الخصائص التي

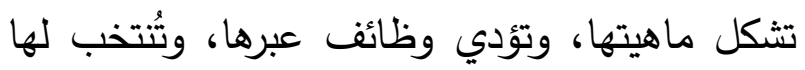

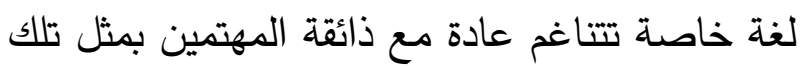
النصوص؛ أي يمكن أن تتدرج في صلب نظرية

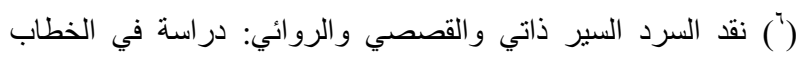

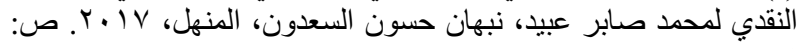

كما يشير لهذا بجلاء واعتراف الكاتب إدواردو غاليانو Eduardo Galeano عن كتابه: (مرايا) الذي نشر بالأسبانية، والذي يرى أن مدخراته قليله.

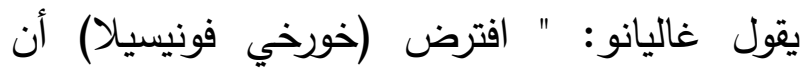
الكتاب لايمكن توفره بسهولة في (بنما) لأنه سيكون

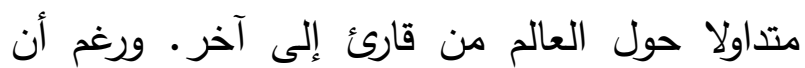
مدخراته لم تكن كبيرة فقد قام برحلة واهمة، استغلها

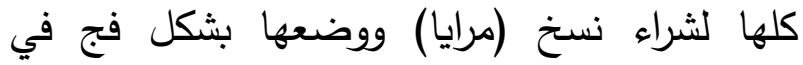
المقاهي والمتاجر والأكثاك وصالونات الحلاقة وفي

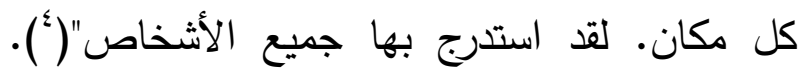
وحول تباين التفسير وسعة الاحتفاء بالنص واستيعابه بشكل أوسع من قبل المتلقي. يقول غاليانو عن كتابه (كرة القدم في الثمس والظل) أردت به أن يفتد

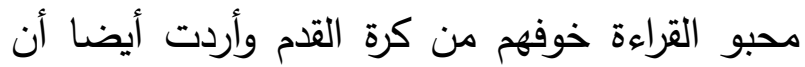
يفقد محبو كرة القدم خوفهم من الكتب، ولم يخطر ببالي ألبتة شيء غير هذا، لكن عضوا سابقا في هن الكونغرس المكسيكي (فيكتور كوينتانا) بلغ به تأثير

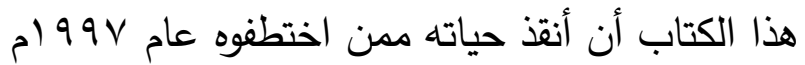
وهناك كان الأثر الآخر (º). النصوص الإبداعية المقصودة تتوزع بين فنون السرد من رواية وقصة قصيرة وأشكال أخرى تتدرج

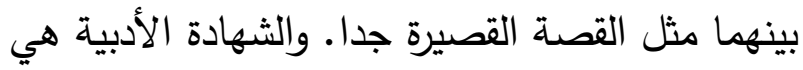

(؛) حياة الكتابة، مقالات مثرجمة عن الكتابة، إعداد وترجمة عبدالله

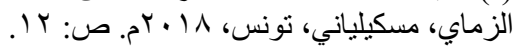

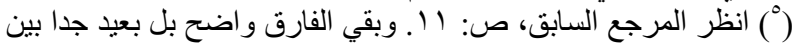

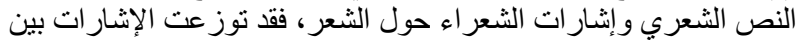

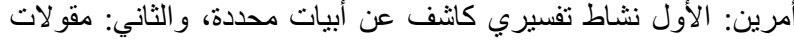

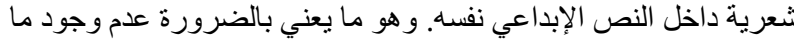
يدعو إلى البحث عن تجنيس هذه الإشار الخدات الشعرية. 
بالإشكال والتشعيب والترامي والتداخل، فالشهادة الإبداعية [...] موقف نقدي جمالي ثقافي نضالي من الإبداع والثقافة والذات والنص والواقع والتاريخ؛ أي لي تقع هويتها البلاغية على تخوم جميع الحدود السردية السائدة "(") . يعضد هذا ماورد في أبحاث (الشهادات) الإبداعية التي تضمنها كتاب ملتقى الرواية العربية والتي كان من ضمنها على سبيل المثال شهادة إدوارد الخراط ('”). كما مال لهذا الاتجاه ولكن بدرجة أقل تعميما إبراهيم نصر في تقديمه لكتاب (مرايا التذوق الأدبي)(' ('). وهو تصور واسع في تقديري وربما تآلف مع مقولة إمبراطورية البلاغة؛ أي إنه استظل بمظلة البلاغة بوصفها خطاب الخطابات، كما يراها محمد مشبال ('rr). كما أن أيمن تعيلب رصد ما أسماه شهادة إبداعية، وجعلها جنسا أدبيا جديدا. وهو تصور يبدو غير مكتمل النمو إذا نظرنا إلى المنطلق الأساسي لبناء نظرية أجناسية تبحث عن حدود مائزة لها وظائف وماهيات، وتمثل الأداة فيها عنصرا جوهريا في رصد فنون الإبداع كافة.

(9) بلاغة الشهادة الإبداعية نحو تأسيس لجنس أدبي جديد، أيمن تعيلب،

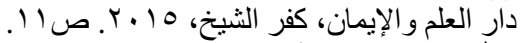

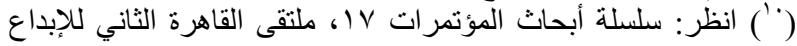

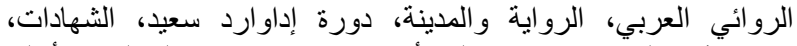

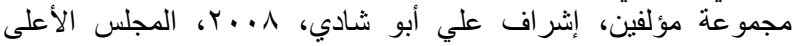

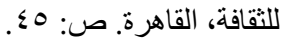

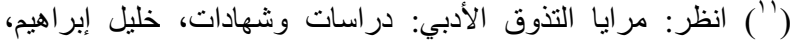

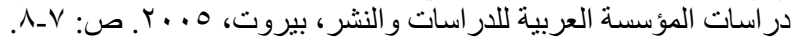

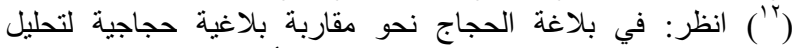

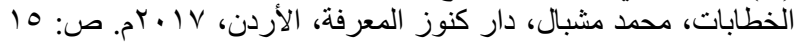

الأدب، وهو ما يعني أن " بناء النظرية الأجناسية

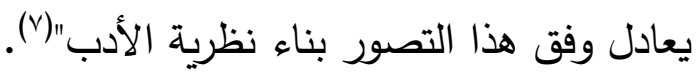
يبقى التساؤل مشروعا في ضوه ما قدمنا: ما الخصائص التي ميزت الثهادة الأدبية بوصفها: نوعا أدبيا في تصور بعض الباحثين؟

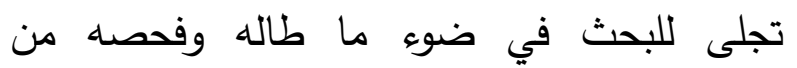
دراسات أنّ هناك تفاوتاً شديداً في تحديد وسم

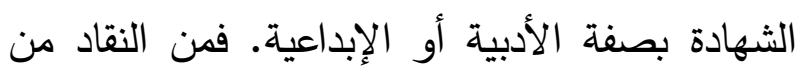

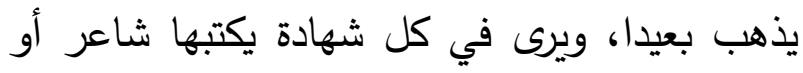

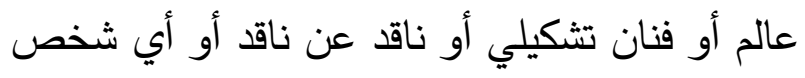

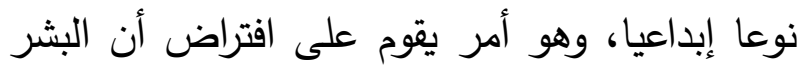

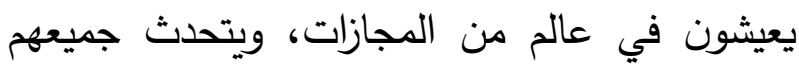

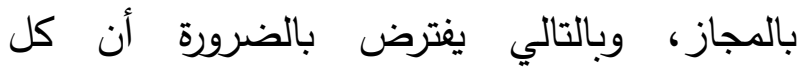

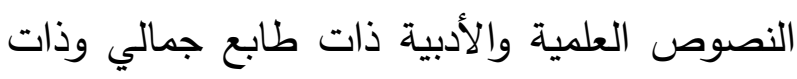
طابع عقلاني، وتتفاوت النصوص في مقدار حظها

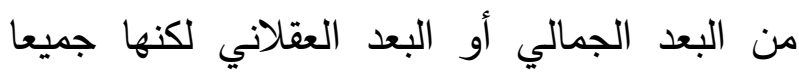
تحمل صبغة سردية. يقول إبراهيم درغوثي: " إن

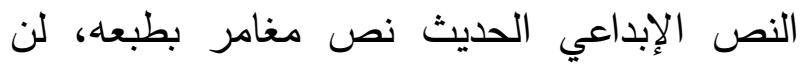
تكتب له الحياة والدوام إلا إذا خرج عن المألوف لهاعن

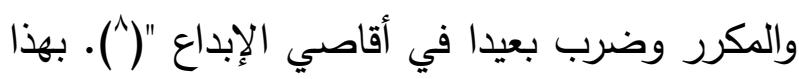
التصور الذي ربما كان واسعا؛ سعى الباحث أيمن تعيلب إلى رصد ما يسميه "بلاغة الثهادة الإبداعية

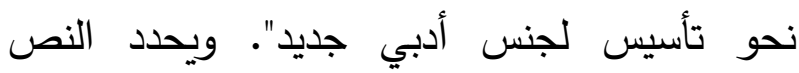
الثهادي بأنه: " تشكيل سردي جامع بامتياز يتسم

(") من الإنشائية إلى الدراسة الأجناسية، أحدد الجوة، قرطاج للنشر

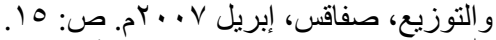
() خارج حدود السرد: شهادات أدبية: قراءات في المشهد الإبداعي

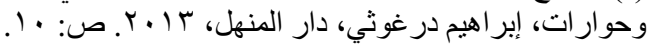


عن ذاته، والآخر غيري يكتب فيه المرء شهادة عن غيره. فالثهادة الغيرية هي تلك التي: " يتحدث بها

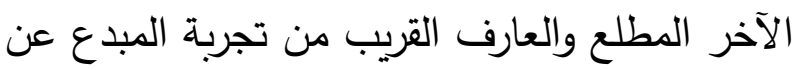
هذه التجربة فيصفها من الخارج ولكن هذا الوصف الخارجي يحمل معرفة خصبة وثرة تعكسها طبيعة

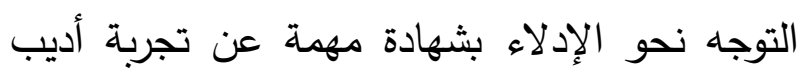

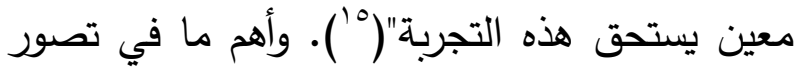
صابر عبيد أنه يؤكد فكرة ارتباط الشهادة الأدبية بالمناسبة بشقيها السابقين؛ أي إنها بالضرورة كتبت التبات

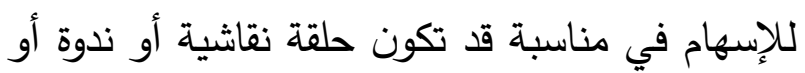
مؤتمرا، وتفاوتها مرهون بتجربة المبدع نفسها. وهو وإن كان يفرق بينها وبين الخاطرة الذاتية فإن ربطها

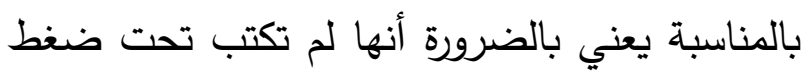

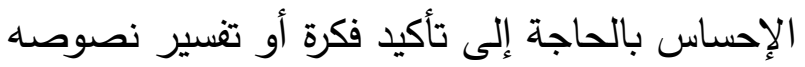

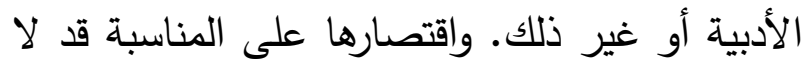

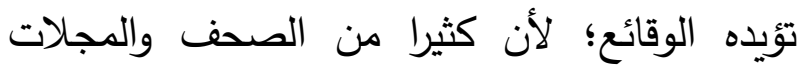
تكتظ بالشهادات الأدبية التي يكتبها الكتاب طواعية

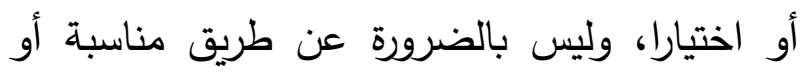

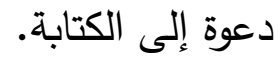

ويطرح محمد الصفراني تصورا يبدو قريبا من تصور

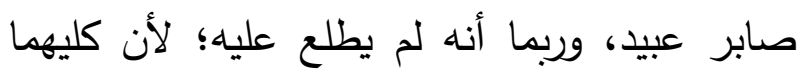
يرى أن الشهادة الأدبية ذات شقين أحدهما: ذاتي يكتب فيه المره عن ذاته، والآخر غيري يكتب فيه

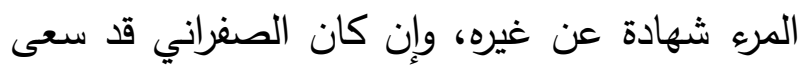
إلى دمجهما في تعريف ثالث يجمع بينهما، بحيث

$$
\text { (") تمظهر ات الثكل السير ذاتي، محمد صابر. ص: 9 ب ا. }
$$

ويصرح محمد صابر عبيد بأن الثهادة الأدبية مظهر من مظاهر السيرة الذاتية في كتابه (تمظهرات الشكل السير ذاتي)؛ لذلك يجعل صفة الذاتية تالية للموصوف الثهادة وسابقة على صفة الأدبية لتكون ( الثهادة الذاتية الأدبية )، ويعرفها بأنها:

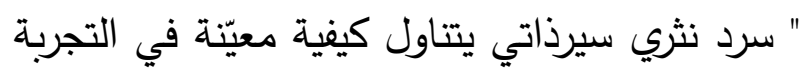
الأدبية للأديب تتاسب المرحلة والمقام والمناسبة [...]

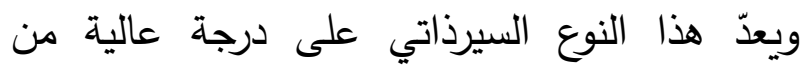

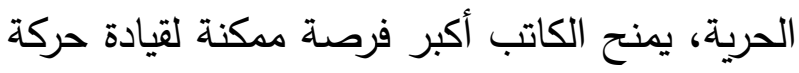
السرد، وتقديم البيانات والأسانيد والرؤى التي تدعم مشروعه الكتابي المركّز والمتمحور حول مصطلح (الثهادة) التي يمكن وصفها بأنها ألصق السرود الترول السيرذاتية بجوهر الحالة الإبداعية الذاتية - منهجاً وخبرة -. وغالباً ما يهتمّ الأديب في صياغة شهادته الإنه باللغة العارضة والهصوّرة والكاشفة والمحللة، ذات

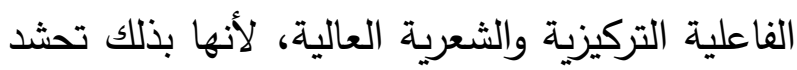

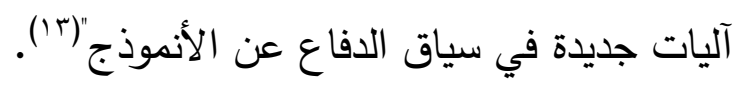

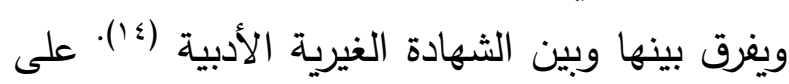
أساس الفرق في التجربة، فالذاتي يكتب فيه المرو

(") تمظهرات الثكل السبر ذاتي قراءة في تجربة محمد القيسي السبر الذاتية، محمد صابر عبداء عبد، منشورات اتحاد الكتاب العرب، دمشق،

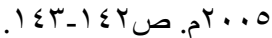

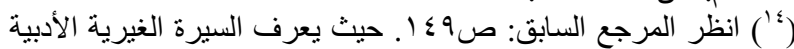

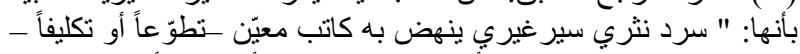

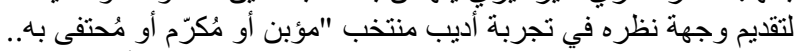

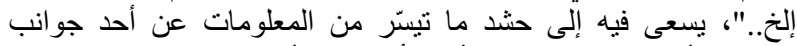

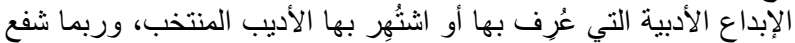

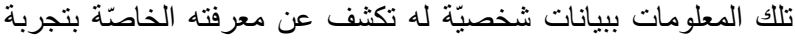

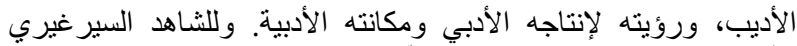

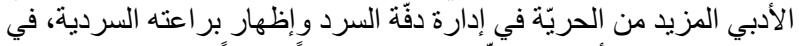

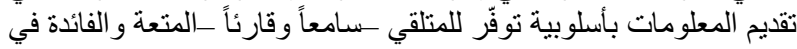

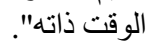


التي ترتفع بها درجة عن المذكرات والسيرة والرواية

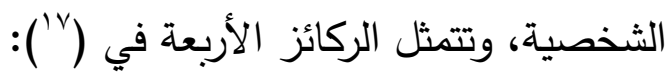
1- شكل الكلام: سرد نثري أدبي (غير تقريري). r- الموضوع: حياة الثخص الفردية. r- التطابق بين المؤلف والراوي. ع- موقع الراوي: السرد التذكري من قبل التروئ الراوي المتطابق مع الثخصية الرئيسية. وتجدر الإشارة إلى هذا الإلحاح على مفهوم الصدق، التحبيه، وهو وإن كان مفهوما قاراً في دراسات السيرة الذاتية

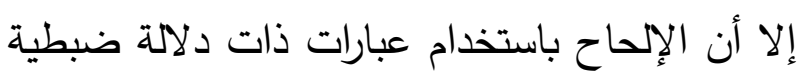
مثل لفظ (الأسانيد) تكثف عن التوجه الإيديولوجي الذي يتوافق مع شخصية الكاتب المسلم الذي يعتمد الإني

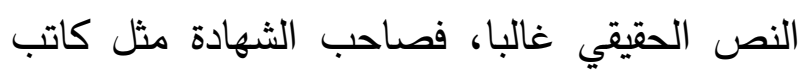
السيرة " مصدق ومؤتمن فيما يحكيه؛ لأنه المرجع

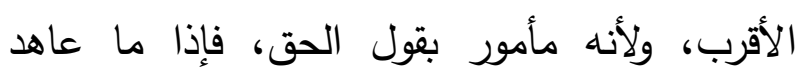

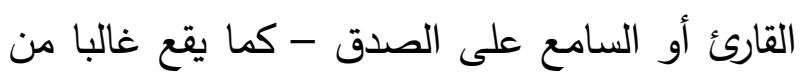
كتاب السير - كان ذلك بحقه آكد وأوجب "( '^ل). في طرح آخر يرى أحمد الحسيني - دون مواربة -

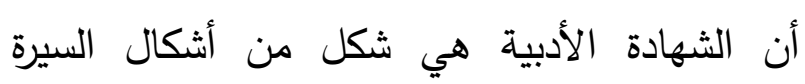
الذاتية الفنية في دراسته الموسومة بـ" آليات السردية التيكال المقاومة في النص السير ذاتي النسوي - شهادة

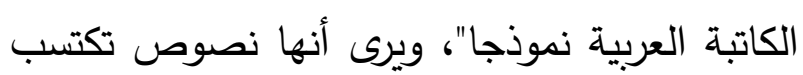
الخاصية السردية وفقا لتصور بارت الذي يرى في

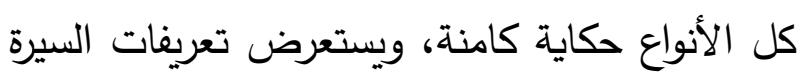

(lv) (انظر: معجم السرديات، إثراف محمد القاضي، الرابطة الدولية

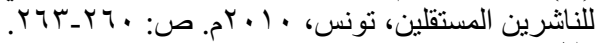

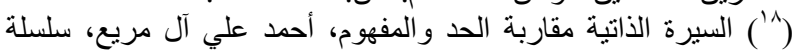

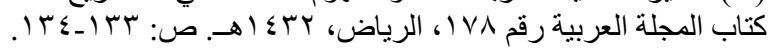

يكون هناك تعريف خاص لكل منهما على أساس

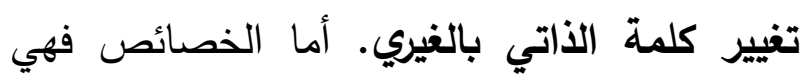
واحدة لا تتغير، ويتخذ من كتابة الثهادة الأدبية

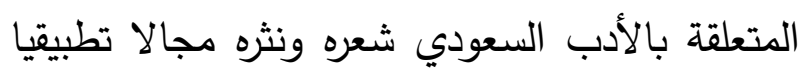
لهذا التصور النظري. وحتى يتضح هذا التصور

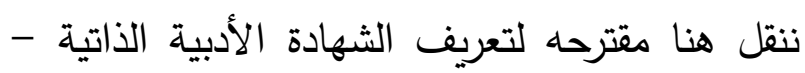

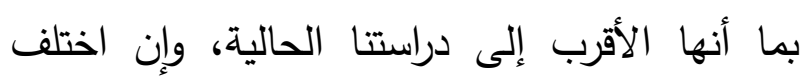
مجال العمل اتساعا وضيقا - يقول الصفراني إنه: " سرد نثري تذكري قصير صادق مدرك بطريقة مباشرة أو غير مباشرة يشها به شخص واقعي على ذاته لإثبات حقائق أو رد دعاوى تتعلق بمسار حياته بـاته

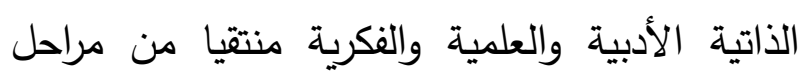
حياته الماضية أبرز الوقائع والمعلومات والتجارب ونكيه والذكريات التي شكلت تجربته الأدبية، وسلكتها في

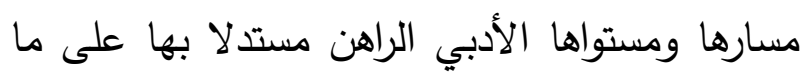

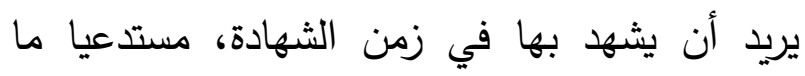

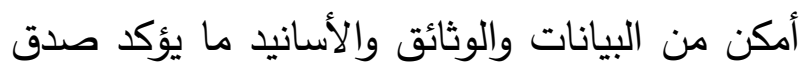

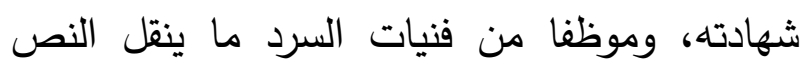

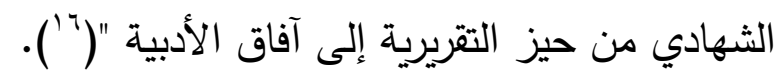

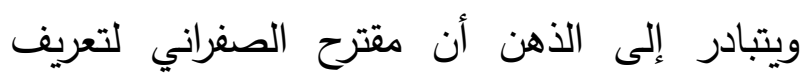
الثهادة الأدبية الذاتية هو عين التين ما طرحه فيليب لوجون Philippe Lejeune لتعريف السيرة الذاتية في صورتها المثلى؛ أي التي تتوفر فيها الأركان الأربعة

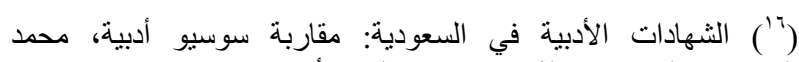

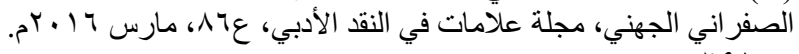

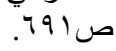


البطركية. وإذا كانت كتابة نسوية فما الداعي إلى وصفها بالمؤنثة؟ وما الذي يميزها عن غيرها من

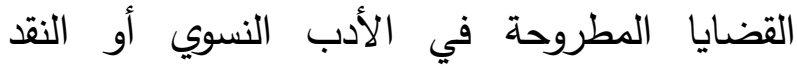
النسائي، فهل يقصد الحسيني تحولها من دور النهائ المتلقي إلى دور الفاعل، وهي على كل حال قضايا تتطلق من ميراث إنساني عام يجعل المرأة دوما في دلي

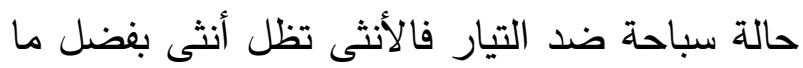
تفتقر إليه من خصائص، كما يؤكد أرسطو

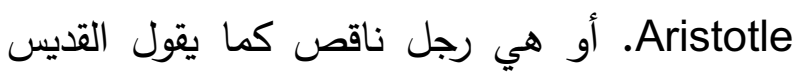
توما الأكويني Thomas Aquinas (rا'). أين خصوصية المجتمع هنا في سياق إنساني عام. أسئلة كثيرة تجعل طرح الحسيني حول الثهادة

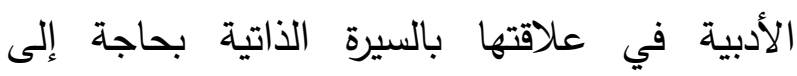

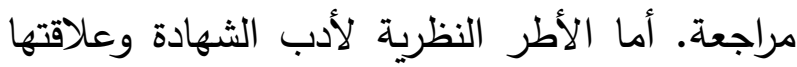
بالمقاومة فهي قريبة مما طرحه كارين كابلان Karen Kaplan 1992 الحسيني- في دراستها: ( السيرة الذاتية المقاومة الأنواع الأدبية الخارجة على القانون والذوات النسوية عبر القومية )( (r) ). وهو كما يتضح يتعلق بمذكرات

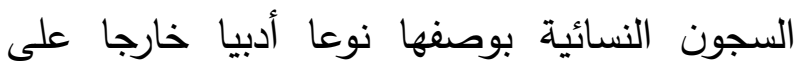

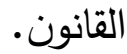

(") انظر: النظرية الأدبية المعاصرة، رامان سلدن، ترجمة جابر المقان عصفور، سلسلة آفاق الترجمة، الهيئة العامة لقصور الثئة الثقافة، القاهرة، (990 1990

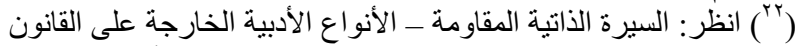

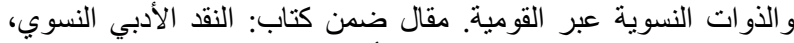

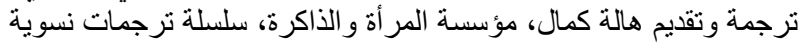

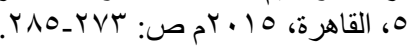

الذاتية خاصة عند فيليب لوجون ليؤكد تطابق

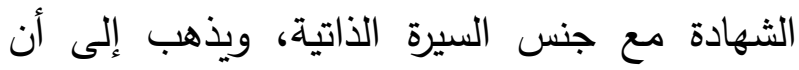
كتابة الثهادة من قبل الكاتبات هو نوع من أنواع المقاومة في مجتمع ذكوري مناهض، يقوم على تهميشهن وقهرهن. وهو ما أبرز مايسميه بالكتابة

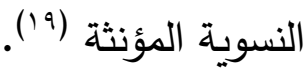
وقد نتفق مع فكرة المشابهة بين النص السير ذاتي

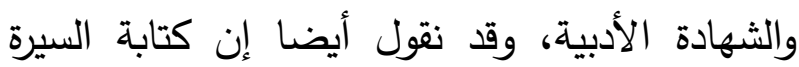
الذاتية الفنية قد تكون مجموعة من الشهادات نشرت

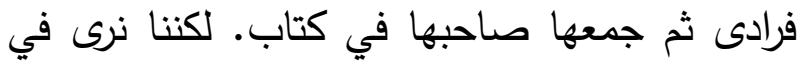
دراسة الحسيني مراوحة بين إلحاق الثهادة الأدبية بالسيرة الذاتية - كما أشرنا في الفقرة السابقة - وبين القول بأن الثهادة نص أدبي غير مجنس، فهو

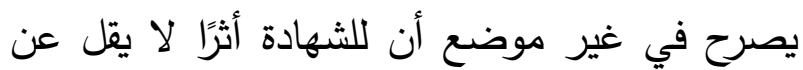

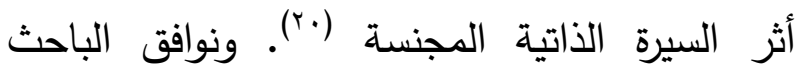
أيضا في أن البيئة الاجتماعية لها دور في صنع النع النيه آليات السرد في النص الثهادي / السير ذاتي لكن

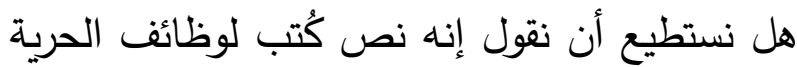

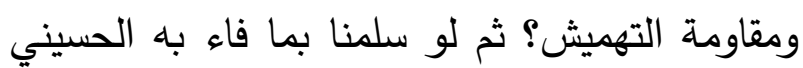
فلماذا يكتب الرجال شهاداتهم طالما هو نسوي؟ وماذا

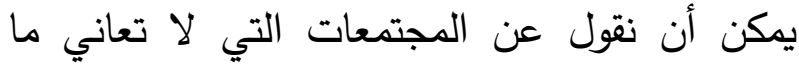

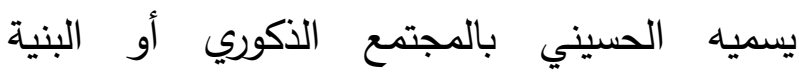

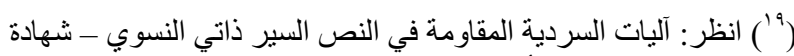

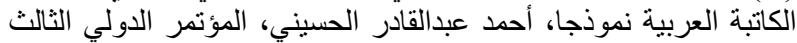

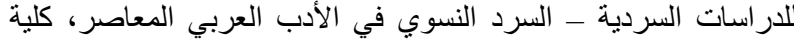

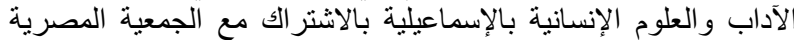

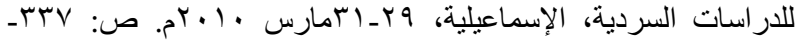


الشهادات الأدبية، وهو ما نحاول بيانه في الفقرات اللاحقة من البحث في إطار نظري تطبيقي في آن عن الثهادات الأدبية للساردات السعوديات. بناء صورة الذات في الثهادة الأدبية: تشكل التجربة صورة الذات في الشهادة الأدبية، ووفقا لنظرية التلقي، تتجلى الذات في صورتين: منتجة ومستهلكة، وتثكل الصورتان الأثر الذي يحدثه فعل في لفرين

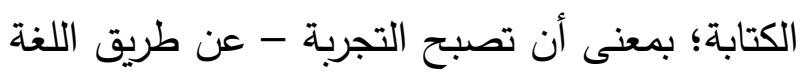

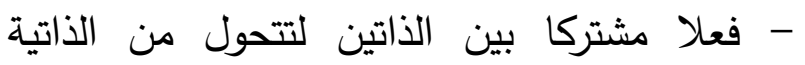
الفردية إلى الذاتية الاجتماعية حيث تجمع الطرفين

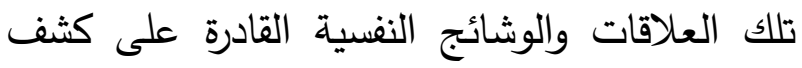
IRENA الظواهر كما يراها: إيرينا مكاريك خاضعة تحت مصطلح Intersubjectivity Intersubjectivity is a key term in phenomenological( $\left({ }^{(\varepsilon)}\right)$. مع قدرة الذات المنتجة على شرح تجربتها.

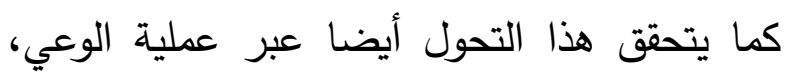

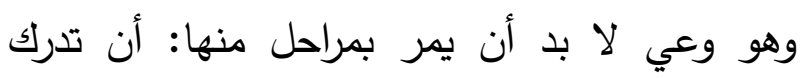

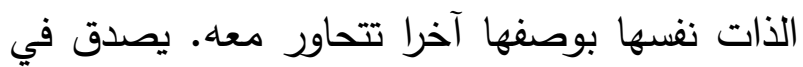

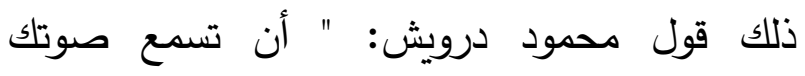
المبحوح يعني أن آخرك قد سامرك، وأسر لك لك لك بأخبارك الشخصية، في غرفة كلما ضاقت اتسع ما لـان وراءها، واحتضنت العالم بشغف المصالحة. وأنت إذ عرئ

Encyclopedia of Contemporary Literary Theory, $\left(^{r \xi}\right)$ Approaches, Scholars, Terms. IRENA R. Makaryk, University of Toronto Press, Canada, 1995. 3/568. وتجد الإنارة إلى أن الموسوعة قد تمت ترجمنها كاملة إلى اللغة العربية

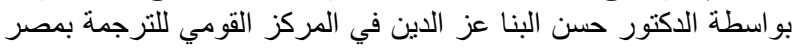
في ثناثة مجلدات.
وهو ما يجعل دراستتا هذه تخلص أنّ مشروعية

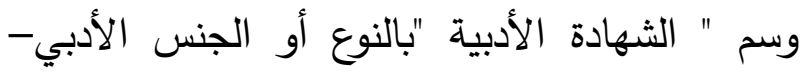

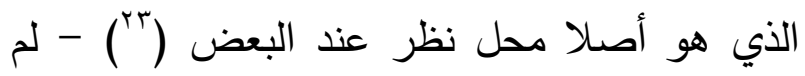

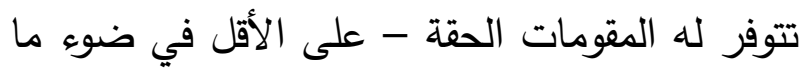
اطلع عليه البحث من دراسات - وأنّ بيان ماهية

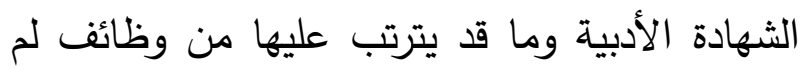
تتبلور بشكل كاف. يبدو القول مفيدا بأنّ الخاصية

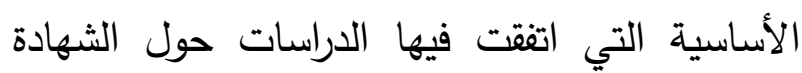
الأدبية أنها تعمل على بناء صورة الذات في الكتابة، وهو ما تحاول الدراسة إبرازه في الفقرات اللاحقة من لن الناء البحث. يضاف إلى ذلك أن حصر الثهادة الأدبية في خانة ما يُكتب تحت (شهادة أدبية)، ويلقى في لتصني مؤتمرات أو يوضع في ملفات لبعض الدوريات مسألة غير دقيقة؛ لأننا نستطيع أن نضيف إلى ذئى ذلك

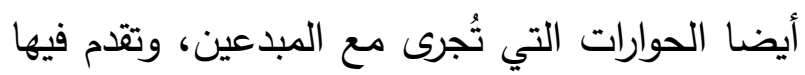

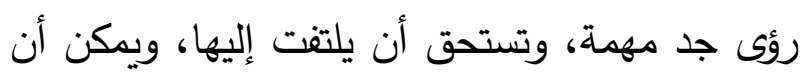
يضاف إليها المقابلات الخاصة التي يقوم بها بعض الباحثين عند إنجاز دراسات أكاديمية حول أعمال المبدعين من المعاصرين لهم. إن كل ما سبق يقدم شكلا من أشكال الشهادة لكنها تتفاوت في المسالك لك الكرين

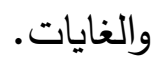
وقد يبدو مفيدا أن نقول إنّ الخاصية الأساسية التي

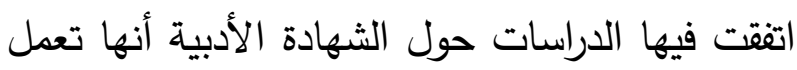
على بناء صورة الذات في الكتابة، وهذه الخاصية وحدها كفيلة أن تقدم لنا تصورا واضح الملامح عن فئ وهن (") انظر: التحولات في الرواية العربية، نزيه أبو نضال، المؤسسة

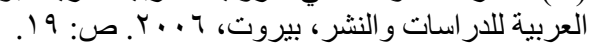


جانبا من جوانب عمله، وغالبا ما تطلب من المبدع مشروطة بالحديث عن زاوية محددة، ويمكننا أن نمثل هنا بملف الرواية والمدينة الذي ضم مجلدا كاملا لشهادات الروائيين العرب حول تجربة المدينة في سردهم، وسأحاول أن أقتطف نموذجا من شهادة لعرد الروائي يوسف المحيميد: " أشعر أن للمكان سطوة ما على نصي الروائي، حتى لولم يكن حضورا علنيا، فهو حضور ضني عبر الثخوص والعناصر والفضاء ذاته. وأحيانا يمكن القبض على على روح المدينة (الرياض) مثلا في رواية (فخاخ الرائحة) ورواية (لغط موتى) كما أنني لا أحب تصنيفي كروائي مدينة، أو كاتب ريف، أو كاتب بحر أو أو صحراء، بل لقد كسرت كل هذه القيود - بقصدية واضحة - في رواية فخاخ الرائحة إذ حضرت المدينة برائحتها و والصحراء بصنها، والغابة

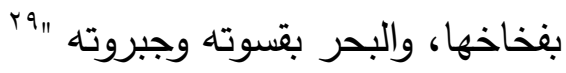
يلاحظ كيف حول المحيميد عبر الثهادة تجربته الذاتية إلى تجربة اجتماعية، وكيف استطاع أن ينفي عن نفسه فكرة التصنيف إلى كاتب ريف أو صحراء عبر قصدية واضحة في النص الروائي كما يشير، وإلى قصدية واضحة عبر الثهادة، ويظل مدار

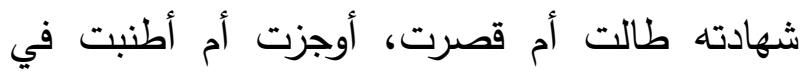
إطار علاقته بالمدينة. كما استطاع الكاتب الروائي

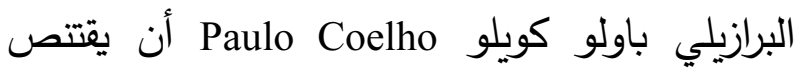

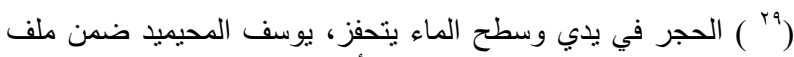

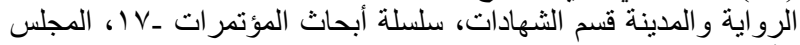

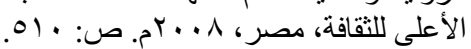

تغني لا تغني لتقاسيم الليل مع أحد، ولا تغني لتقيس

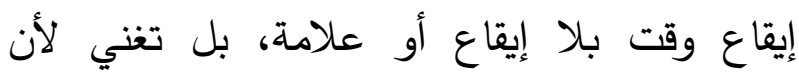

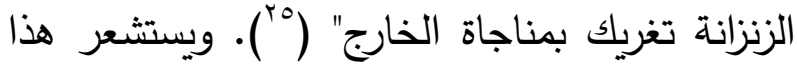
التتاغم إخلاص عطا الله بقوله: "... وثمة رباط

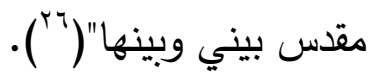

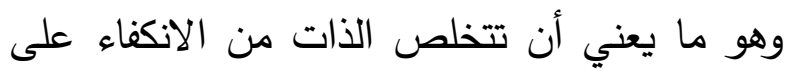

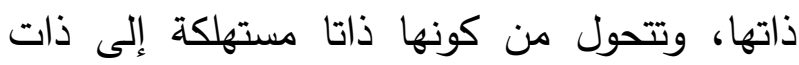

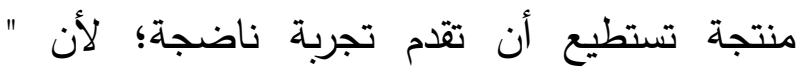

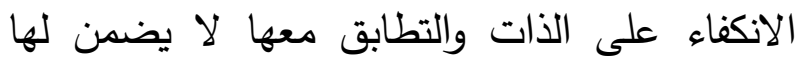

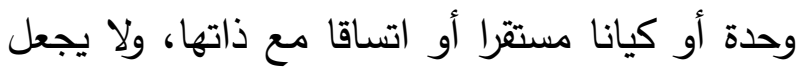
منها ذاتا متيقنة من ذاتها، عارفة بها، مهيمنة عليها وعلى عالمها. إن الوعي يدفع بالذات خارج ذاتها،

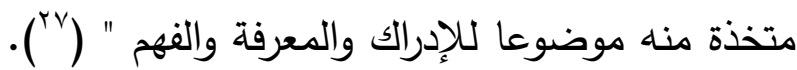

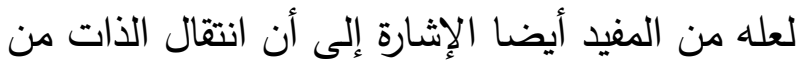
الفردية إلى الاجتماعية تعني فيما يتعلق بالشهادة

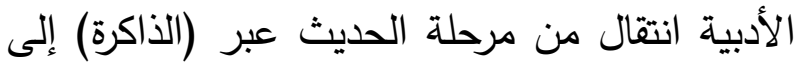
الحديث عبر (الوعي). الذي يعتمد على مصادر جماعية وبالتالي هو "صورة من صور الاعتراف

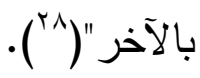
يتيح هذا الشرح للذات فرصة التعبير عن نفسها في موقف محدد أو في تجربة محددة تضيء للقارئ

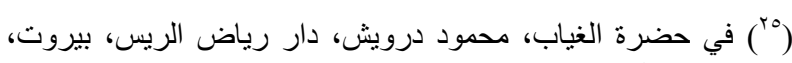

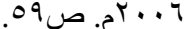

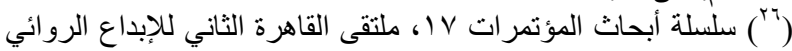

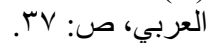

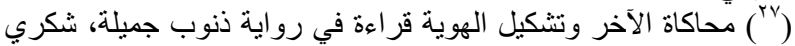
الطوانسي، أبحاث المؤتمر الدولي الخامس للارداسات السردية التردية، الجمعية الصصرية للار اسات السردية بالاثتر الك مع مركز اللغة العربية و الترجمة

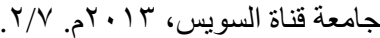

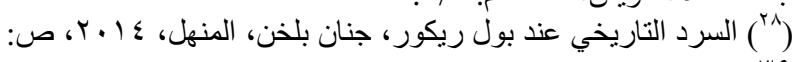


وجه محدد من نصيب الذات ووجوه حياة الكاتب (") (َ). ولا مراء من تحقق استفادة الكتاب المعاصرين

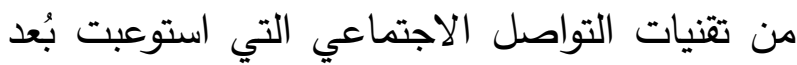
إضافيا من مراد كاتبها كالفيس بوك وتويتر، مما يعد نافذة مباشرة وسربعة التفاعل؛ لذا تتشط فيه أعمال بعض الروائيين ك باولو كويلو الذي يحظى بمتابعة عالية في العالم تبلغ عشرات الملايين وحينما سئل عن ذاك أجاب: " هي طريقة إضافية تمكن الكاتب من التواصل مع قراءه والاطلاع على وجهة فئه نظرهم... فالكاتب سابقا كان يمرر أفكاره عبر الروايات فقط أما الآن فيستطيع ذلك عن طريق منشور قصير على مواقع التواصل الاجتماعي"( عَّ). وما يعنينا ظهوره هو الدور الفاعل للذات؛ أي ذلك الكي الحضور الطاغي لها. وفي السياق نفسه يؤكد غالب هلسا عدم إدراك النقاد للبعد الذاتي في نصوصه إذ

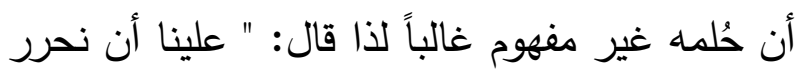
أنفسنا من المواضعة الاجتماعية، ونترك تجربتنا تعبرعن نفسها... فداخلنا أغنى بكثير من فكرنا

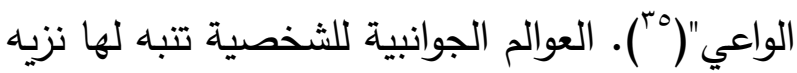
أبو نضال حين قال: " نجدها دائما تأخذ شكل سيرة ذاتية لغالب نفسه... والسيرة هنا ليست مجرد سيرته الخارجية المعروفة، بل هي أساسا سيرته الجوانبية

("آ) في نظرية السبرة الذاتية (المصطلح، الأنواع، الحقبقة والخيال )،

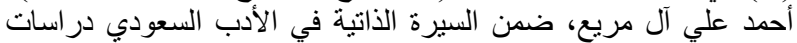

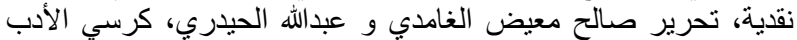

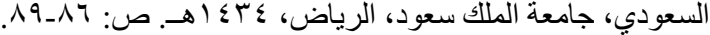

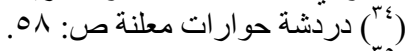
r ( )
فرصة الثهادة لينفي عن نفسه ما عرف عنه عالميا

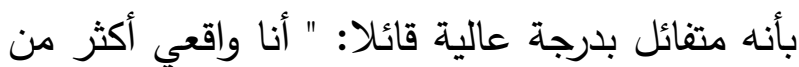

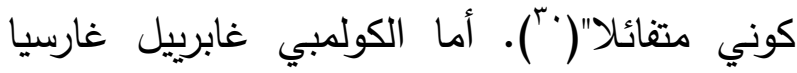
ماركيز Gabriel García Márquez فوجد في الثهادة نافذة يقدم عبرها اعترافه بأنه لم يجنح لبلد آخر

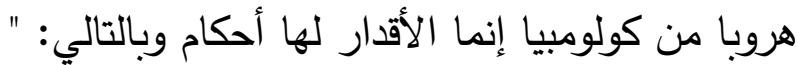
أنا لم أنس بلدي إنه كلام فارغ. وفي أملي ماندان أمارس فيه فعل الكتابة فأنا أكتب رواية كولومبية بلا فلان شك"("). ). وعندما اتهم أحد أشهر موسيقيي القرن

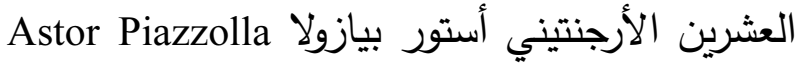
بأنه حارب التانغو الكلاسيكية عبر مؤلفاته، عبّر بقوله من خلال الشهادة: "لا، ليس صحيحا، لست ضده. ببساطة أملك نظريتي الخاصة التي تتمثل في لهن لهن صنع موسيقى مختلفة. المشكلة في الأرجنتين يمكن أن تغير كل شيء عدا التانغو، كان التانغوا يعتبر بمنزلة الدين، تكرار دائم لذات الفعل ضمن حلقة مغلقة لا يمكن الخروج منها"( بَّ"). ويمكننا أن نقول إن عددا ليس بالقليل من الكتب

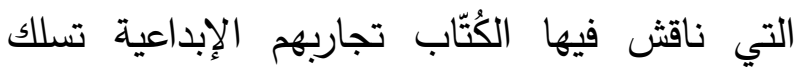

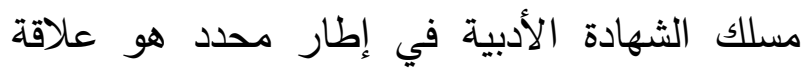
الكاتب بجانب محدد من أنماط حياته؛ لذلك وصفها بعض الباحثين بسيرة ذاتية جزئية، تحمل عناوين:

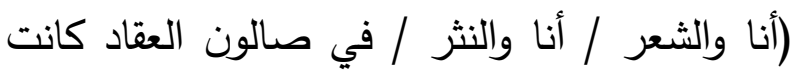

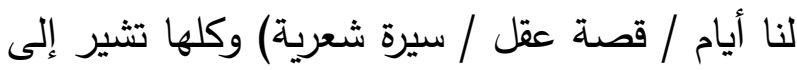
(•) دردشة حوارات معلنة، إعداد وترجمة أمل فارس، دار ممدوح

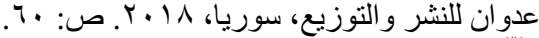

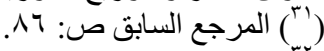
(") المرجع السابق ص: 97 (T) 
ومتابعات)(وَّ). وفي كتاب (حوارات في الرواية العربية) تؤكد الروائية اللبانية علوية صبح في روايتها (اسمه الغرام) "... لكني بالتأكيد لا أفكر أثناء الكتابة لتهبه

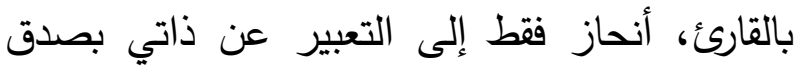

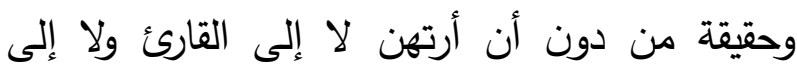

$$
\text { الأفكار والخطابات المسبقة..."(· ؛). }
$$

ويبقى التساؤل: لماذا يلجأ المبدعون إلى شرح تجاربهج? أليس هذا عمل النقاد؟ ولماذا لا يتركونها

\section{شوارد يسهر الخلق جراها ويختصمو!!}

مؤكد أنّ بناء صورة للذات يقتضي أرضية معرفية مشتركة بين الذات المنتجة الفردية والذات المستهكة الجماعية؛ بمعنى أن بناء صورة ذات يقتضي ترسيخ مجموعة من العوامل المشتركة، وهذه العوامل قد تصيبها بعض التشويش نتيجة لسوه قراءة - في تقدير الذات المنتجة - من قبل المستهلكين، ومرد هذا منطقا طبيعيا تتمايز فيه التراكمات الثقافية وأبعاد التجربة الشخصية بين المستهلكين؛ لذا صار الإدلاء بالشهادة الأدبية من شأنها أن تقيم علاقة تفاعلية تزيل اللبس، وتعيد العلاقة بما يستوجب أحيانا إبرام وثيقة تؤكد فيها الذات المنتجة عدم خرقها ل (منطقة

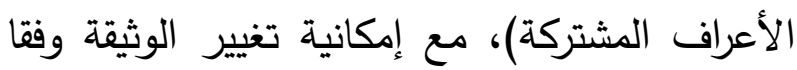
لرؤية الطرفين لثبات هذه الأعراف وتحولاتها. وأحيانا يُمنح النص مساحة تلتغي تلك الحدود معها ليكتسب

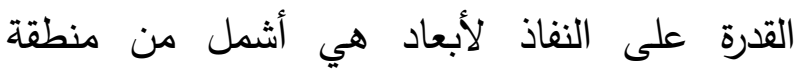

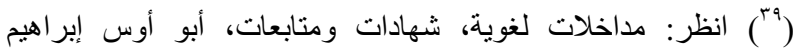

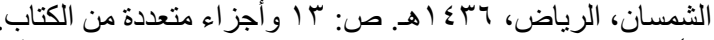

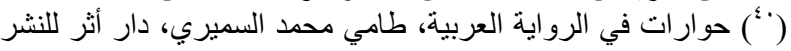

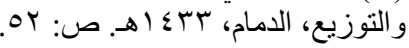

سواء في عالم اللاوعي أو عالم الطفولة"(بَ). وربما رنى البعض إلى شخصيات قريبة من واقعه فتلبسها

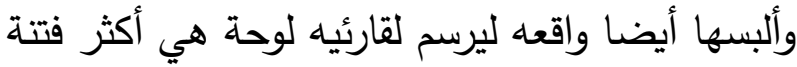

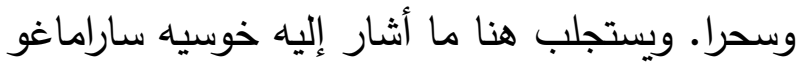
José Saramago في ستوكهولم: "... كتبت هذه الكلمات منذ ثلاثين عاما تقريبا دون أي غاية أخرى سوى إعادة بناء وتسجيل لحظات من حياة الأشخاص الذين عملو

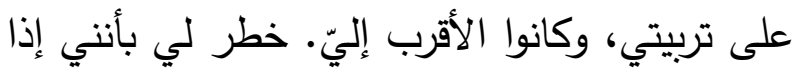

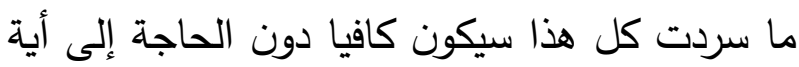
إضافات أخرى لكي يتمكن الآخرون من معرفة

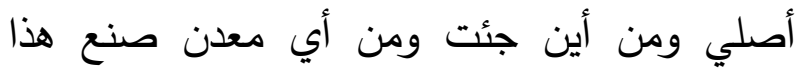

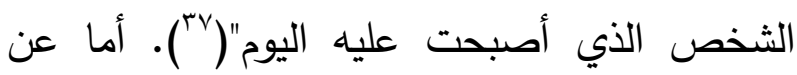
صورة الذات التي بناها هذا البرتغالي فيمكن اختصارها من بعض ماكتبه: "يمكنني القول إنني

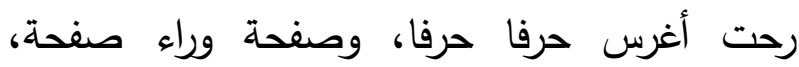
وكتابا تلو الآخر في الرجل الذي كنته جميع الشخصيات التي خلقتها. وأعترف بأنني من دونها

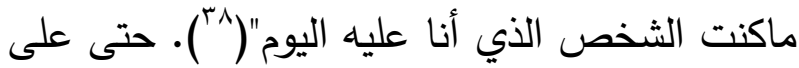
مستوى الكتابة العلمية تبقى صورة الذات حية حين تبنى بين أضلع الشخصيات الأخرى وبالتالي يتتفسها الآخر وتظهر للقارئ مع كل نَفَسٍ يمر من تلك الأضلع كما بدا جليا في كتاب شعهادات 
وأن تواجه الكاتبة السعودية هديل محمد وهي تدلي بشهادتها حول نص إبداعي مُحدد، هو روايتها: (ذاكرة السرير) بهذا التساؤل: الاغتراف من السيرة الذاتية في السرد إلى أي حد كان، بمعنى كيف كان انضباطك في الالتزام بما هو سيرة ذاتية وبين ما هو متخيل؟ وتكون إجابتها يغلب عليها الطابع الانفعالي التبريري نحو: "لم أكن بحاجة لانضباط لكوني غير ملزمة بأمانة النقل، نعم أُصول روايتي مستمدة من الواقع لكني بعد رصده أضفت وعدلت واستبدلت

$$
\text { بعض الأمور" ( (")). }
$$

فإذا أردنا أن نمعن النظر إلى طبيعة هذه العلاقة في ضوء شهادات الساردات السعوديات سنتبين أن هناك مرحلتين أساسيتين؛ هما: البحث عن هوية، ثم القضايا المتعلقة بالذات. المحور الأول - البحث عن هوية /الثهادة الأدبية ولعبة التخفي وأرمي هنا أن الساردات أو بعضهن كن يتخفين في أسماء مستعارة، كقنطرة تمر بها الكاتبة في بداية رحلتها ليس فقط في الوطن العربي بل حتى في العالم الغربي حيث نتذكر حال الكاتبات الإنجليزيات والفرنسيات في القرن التاسع عشر كالشاعرة والروائية جورج إليوت George Eliot و روبرت غالبريث The Brontë والأخوات برونتي Robert Galbraith George والروائية الفرنسية جورج صاند Sisters Sand وهو ما يتماشى مع حال كثير من الكاتبات

$$
\text { ("rr }
$$

الاتفاق، حيث يتسع الأفق حينها لاكتشاف ماوراء ظاهر الأشياء متحديا طمأنينة الاتفاق، وهنا ربما يتلقفها أحد الطرفين بالرضى التام حيث يعدها مكافأة في النهاية. وليس أدل على ذلك من تلك القراءات النقدية (المستهلكة) للسرد الحديث، فقد مال عدد ليس بالقليل إلى عقد قران بين صورة البطل وكاتب النص؛ أي التماهي بين المؤلف والراوي البطل أو إحدى الشخصيات، ويزداد هذا التماهي كلما قلّت التجربة الإبداعية من أحد الطرفين؛ وهكذا صارت الشخصية في النص السردي التخييلي محاسبة أمام المجتمع، ولم تعد الأقوال السردية هنا إلا أفكارا تعمل على خدمة المجتمع أو هدمه. وهو ما دفع الكثير من الروائيين السعوديين - على نحو ما يشير الغامدي - إلى كتابة شهادات أدبية لتبرئة ساحاتهم، أو بعبارة أخرى عملت الذات المنتجة إلى كتابة من شأنها نقل تجربتها الذاتية بصورة أخرى حتى تستعيد علاقتها التفاعلية مع الذات المستهلكة، هكذا يقول محمد علوان واصفا عمل نقاده: " قراءة اجتماعية في جسد المؤلف بدلا من قراءة نقدية في جسد النص "

(") ) راجع: السيرة الذاتية في الأدب السعودي دراسات نقدية، نحرير

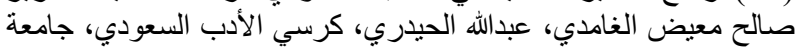

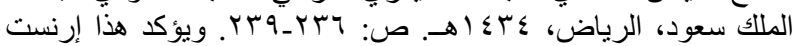

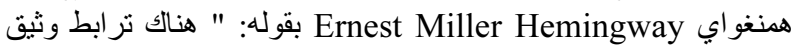

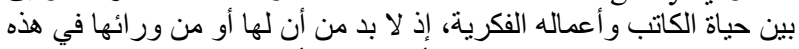

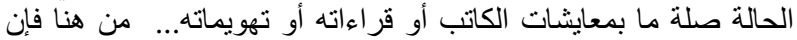

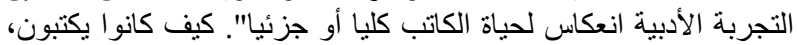

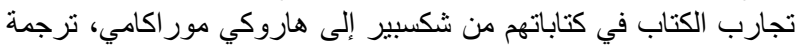

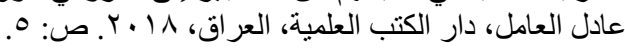


وقصص مترجمة، خلق لاي تمردا نصوصيا، وجعلني أبتكر لنصوصي لغة سردية تتجاوز عين

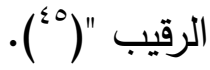

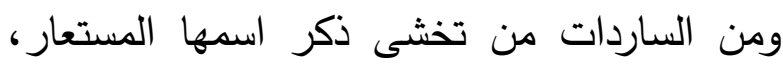
وهي في شهادتها أي بعد أن صار لها اسما معروفا؛

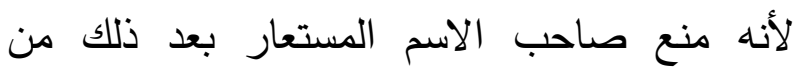
النشر، تقول شريفة الثملان: " مرة واحدة في أواخر الثمانينات كتبت قصة قصيرة باسم مستعار ... وهي لترني

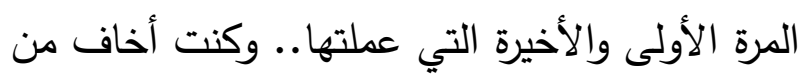
مغبة نشرها، وعندما نشرت جاء أمر بمنع الكاتبة

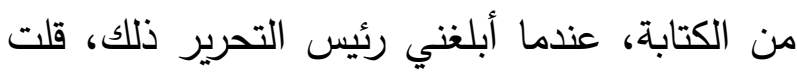

له ببساطة: خلاص لن تكتب بعد اليوم "( آ). ومن الساردات من نوّع في الأسماء المستعارة فاستعار أكثر من اسم كما فعلت حكيمة الحربي التي

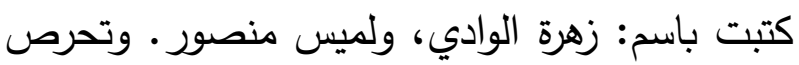

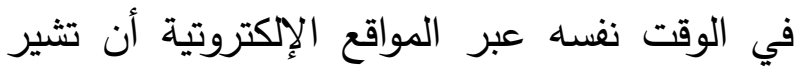

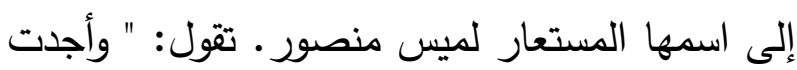

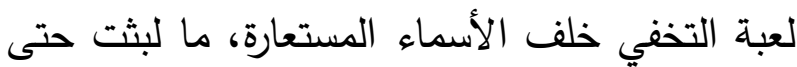

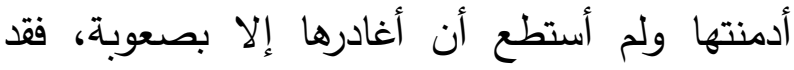
حكمت على نفسي بالسجن دون أن يفرض علي.

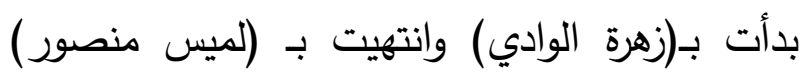
$(\varepsilon v)_{n}$

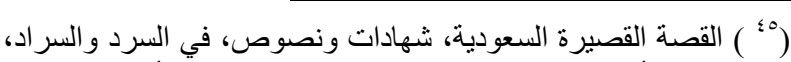

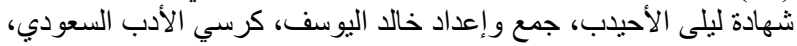

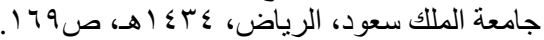

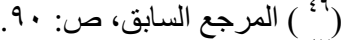

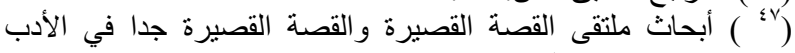

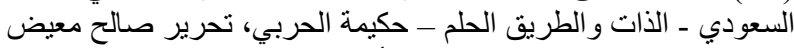

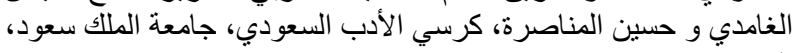

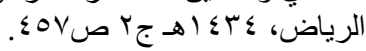

السعوديات " اللائي يردن بالكتابة الخروج من مكمن

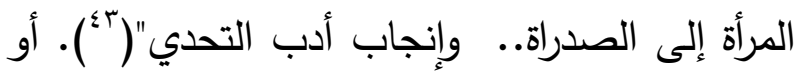
يتخفين عن عين الرقيب في سردهن، عندما كان ظهور المرأة على الساحة غير معتاد، مثل أعمال سميرة خاشقي التي كتبت تحت مسمى بنت الجزيرة. وهو ما يمثل إثكالية كيف تبني الذات صورتها في ظلال التخفي؟. لعبة الأسماء المستعارة لعبة منتشرة عند العرب وغيرهم من الأمم، وقد

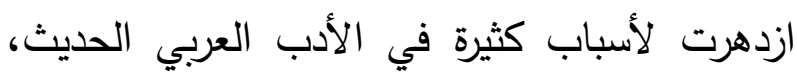
وشكلت ظاهرة في الأدب السعودي الخاص نتيجة مجموعة من العوامل، يحصرها المطوع في: الباعث الذاتي النفسي، والباعث الأدبي، وباعث اضطراي، وباعث مادي، وباعث مزاجي ذوقي، وباعث يتعلق بتوجيه القارئ إلى المكتوب وليس إلى شخصية

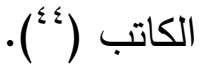
ويمكننا أن نناقش صورة الأسماء المستعارة من واقع شهادات الساردات، وتبدو الملاحظة الجوهرية أن الاسم المستعار لم يكن دوما وسيلة التخفي، فمن الساردات من تثير إلى طرق أخرى للتخفي عن

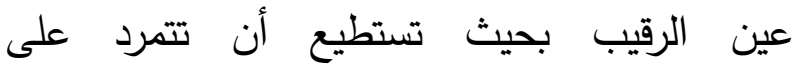

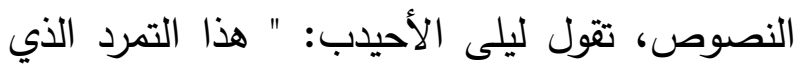

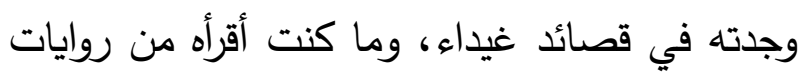

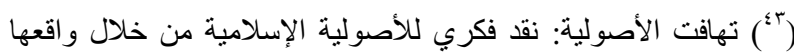

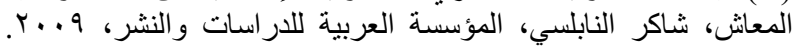

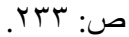

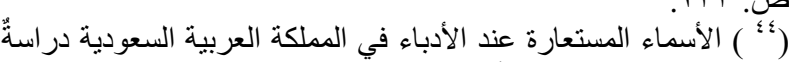

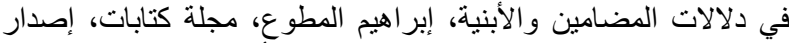
خاص، الجمعية المصرية للاراسات السردية، أكتوبر - نوفمبر ديسمبر الهاتي 
بوصفها نظاما رمزيا يحفظ تاريخ وأعراف المجموعة البشرية التي تتضوي تحتها، ويحكم علاقات الأفراد. ووظيفة القبيلة في الظاهر الحفاظ على تقاليد المنتسبين إليها. لكن لها غاية مضمرة حيث تصبو

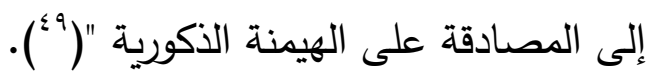
إذن لعبة التخفي كان لها دور مهم لكن دورها اختفى مع التحولات المجتمعية والتشكلات المدنية التي تعزز دور المرأة في المجتمع. كما أن للنزوح المدني تجاه المدن دور جلي ساعد على إبراز معالم

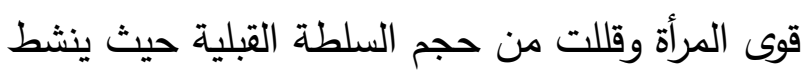

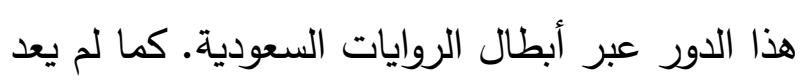

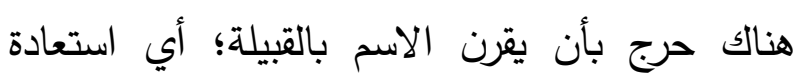

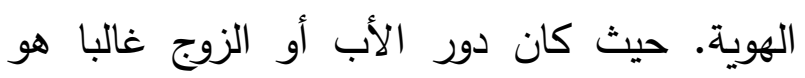

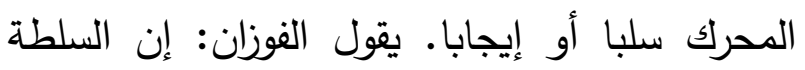

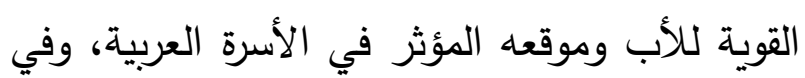
الأسرة السعودية خاصة؛ إما مثبط أو داعم تجاه

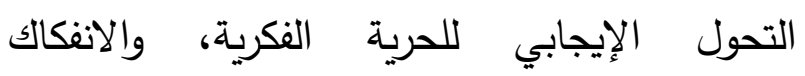
الاجتماعي، حيث تقدم بعض الروايات عددا من المشاهد المتناقضة لدور الأب في شأن التئ التحول

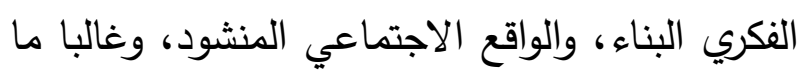
تكون المدينة حاملة للقرار الإيجابي تجاه دور المرأة

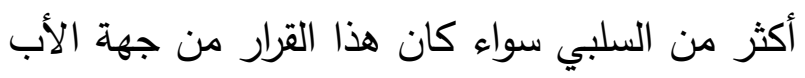

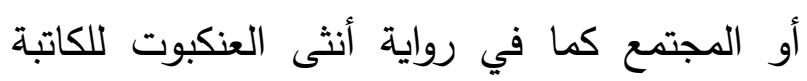

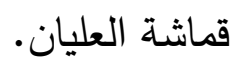

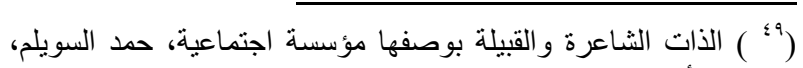
مؤتمر الأدباء السعوديين الخامس، وزارة الثاء الثقافة والإعلام، السعودية، ( )
يبدو مؤكدا أن الشهادات التي بين أيدينا كتبتها روائيات أو قاصات بأسمائهن الصريحة؛ أي إنّ هذه إنه الثهادات كتبت في ظل وعي بحضور المرأة في المجتمع بوصفها شريكا فاعلا في المجتمع. ويبقى ولى بهردي التساؤل حول رؤيتهن للعبة التخفي أو الأسماء المستعارة بوصفها كاشفة عن بناء صورة الذات بالمعنى الذي قدمنا له.

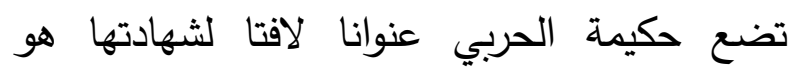
(الذات وطريق الحلم)، وتكشف فيه أولا اللوم الذي لهي لهني

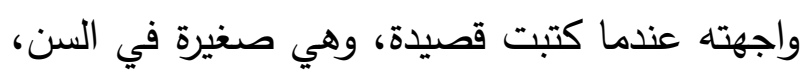
تعبر فيه عن لواعج الحب، وكيف كان أثر هذه فئه الحادثة في تقدصها التخفي بالأسماء المستعارة، ونداء

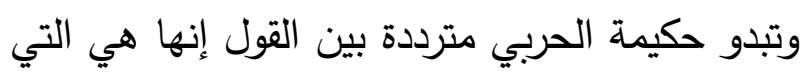
ورطت نفسها في هذا الأمر دون أن يطلب منها ذلك، وبين إلقاء الذنب على القبيلة. والحق أنها ورطت نفسها لا غير في ذلك؛ لأن الثعر بطبيعته

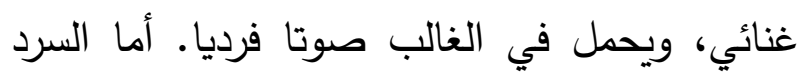

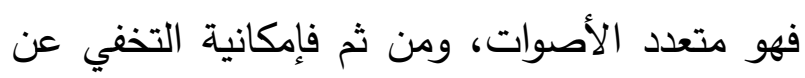
عين الرقيب كما تقول ليلى الأحيدب ممكنة. وأجابت

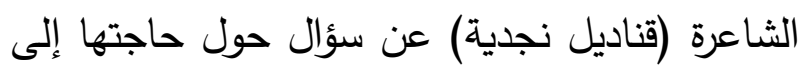

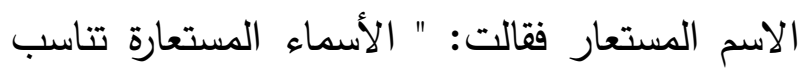

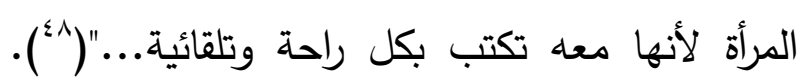
ويظل البحث عن توحد صورة الذات / القبيلة مسألة مهمة لتحقيق الحلم، وإن تعثر فليس من سبيل إلا توحلا

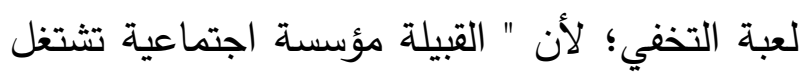

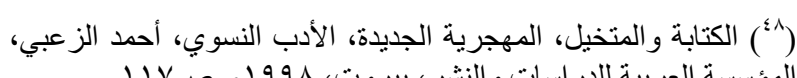


سلطة الدين. ولقد كانت هجرة رسولنا محمد وتأسيس الدولة الإسلامية في المدينة المنورة بمثابة التأسيس المباشر لحضارتها و وتتميتها وتنوع الأطياف الاجتماعية فيها وبناء الذات وتنمية الفرد والحرية ومساحة الاختيار بطرق عديدة، وكان من أهم الإنجازات وضع حد لما كان قائماً فيما يتعلق بالسيادة الغردية، وهيمنة سلطة القبيلة، والعقل الجمعي، وإلغاء الذات والانكفاء القسري في القبيلة، فكان التحول إلى مساحة حضرية في حمى المدينة تكفل تحقيق مبتغى الفرد.("). لذا نجد أن المرأة المدنية المعاصرة على وعي بحقها الاجتماعي والذاتي السليم، حيث مرحلة ترسيخ الوجود. تشير لهذا أمينة الجبرين بقولها: " وها تحن نجد المرأة المعاصرة تطرق مرحلة جديدة من الوعي الرامي إلى استعادة الذات" ( (م). ولم يقتصر الأمر على السرد متعدد الأصوات بل امتد إلى الشعر ومنه الغنائي، وبات مقبولا أن تنشر المؤسسة الحكومية دواوين تحمل انتقادا موجها من الذات إلى القبيلة وإن كان على سبيل المجاز ، بديلا عن البحث في توحد الذات مع القبيلة، كما في صوت هند المطيري: (كء). الله واحد والعمر واحد والقلب واحد ويح القبيلة

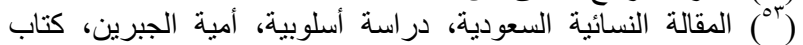

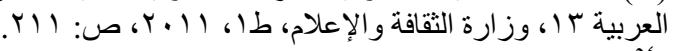

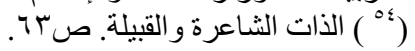

"The strong power of the father and his influential position in the Arab family, and in the Saudi family as an example, is either an inhibitor, or supportive towards a positive some transformation in intellectual freedom novels that presents the positive role of the father in constructive intellectual transformation... Ahlam, the main heroine of the novel 'Unthā Al-'ankabūt, who has become able to run and manage her own businesses in the city and to write under her real name" $\left({ }^{\circ \cdot}\right)$.

كما يؤكد (الأمين) أن المجتمع السعودي بطبيعته أبوي للغاية، حيث الأدوار الرئيسية للمرأة هي دور الأم والزوجة والإبنة، في حين أن دور الرجل الأساسي هو دور العائل:

"Saudi Arabian society is very patriarchal in nature, where a woman's primary roles are those of mother, wife, and daughter, whereas man's primary role is that of the breadwinner" $\left({ }^{01}\right)$. وقد تكون القبيلة تستفيد من احترام الإسلام لوضع الوالدين، لكن بعض الآباء ذهبوا بعيداً في هذا الصدد، لدرجة استغلال هذه المكانة بالأذى. ولم يجمح هذه السلطة إلا النزوح تجاه المدن وما تحتويه من فروقات لحياة الفرد فيها والتي بالتأكيد أعطت ضوءا وانغراجا. حيث يرى الفوزان: أن امتداد سكنى برو المدن كانت منفسا ومساحة لانعتاق الفرد من بعض قيود القبيلة السلبية التي كانت سلطتها أحيانا تتجاوز

The City and Social Transformations in Arabic Literature: ( $\left.{ }^{\circ}\right)$ ), Abdullah H A $r \cdot 11$ 19^•) The Saudi Novel as Case Study( Alfauzan, for the degree of Doctor of Philosophy, University of Leeds. 2013. P: 146, 257. Elamin, A. M. O. Katlin 2010. "Males' Attitudes towards ( ${ }^{\circ}$ ) Working Females in Saudi Arabia". Business and EconomicsManagement, vo1. 39. 746-766. P: 754. 
الحرية المتاح للمرأة لا يختلف عن سقف الحرية المتاح للرجل، من حيث مناقشة القضايا الحساسة، وخاصة القضايا الاجتماعية والسياسية"( †o). وهو ما يجعل من شهادتها رؤية ذات خطر بالتطورات المجتمعية. وتحاول نورة القحطاني التطرق لهذا عبر رصد أقوال بعض النقاد في شأن استجابة القارئ واستقباله للنص (10). ففي الوقت الذي كانت تبحث فيه الساردات عن الاسم/ الهوية، وطمس معالم الأسماء المستعارة تبقى إشكالية التلقي الإيديولوجي أو ما يمكن أن نطلق عليه التلقي للسرد النسوي،

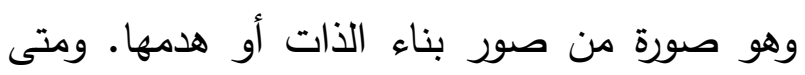
انفكت المرأة من لغة الجمع البكائية ضد الرجل واتجهت للغة الفن كانت استجابة التلقي أدعى كما

$$
\text { يشير لذلك حسن النعمي (199. }
$$
يمكن تبين خطورة هذا التلقي إذا أدركنا هذه الطفرة في الكتابة النسوية على مستوى (الكم)، ومشوبة بالضعف الفني على مستوى الكيف؛ لأن كثيرا من الساردات عبرن عن رفضهن لما يمثل خطورة على الذات الأنثوية في مقابل الهيمنة الذكورية، وهو رفض قد يكون له ما يبرره لكن المدهش أن الرائج إعلاميا هي فكرة الرفض في حد ذاتها، وانتقاد قيم المجتمع السعودي بشكل خاص، وهو ما لا يمكن قبوله من روايات ذات ضعف فني على نحو ما

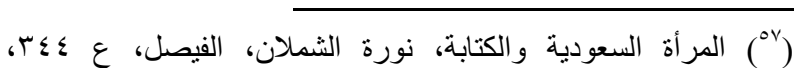

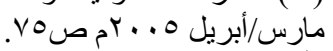

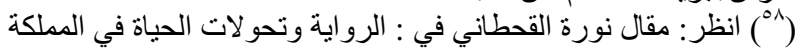

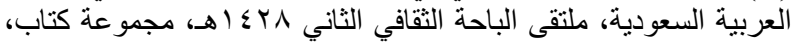

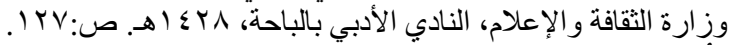

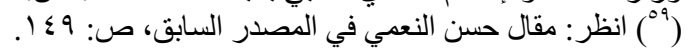

كيف تفسد أرواحنا

كيف تسرق أعمارنا كيف تقسم أحلامنا كالغنيمة وهو ما يعني أننا لن نجد في شهادة الساردات ممن مارسن الكتابة في السنوات العشر الأخيرة حديثا عن من الأسماء المستعارة، وأن التجارب التي خضنها ليست مشابهة لتجارب السابقات. حيث نجد تجربة خيرية السقاف و "أربعة عقود من الإنجاز الأكاديمي والإبداع الإداري والصحفي... عميدة لمركز الدراسات الجامعية للبنات لسبع سنوات. عبرت عن تجربتها الكتابية وارتباطها بالأرض... قادت ركب العشرات في العمل الصحفي النسائي الرائد"( ${ }^{00}$. تجربة فيها التباهي لحقيقة مكانة المرأة. ولعل هذا هو ما دفع ليلى الأحيدب أن تسأل " هل الجيل الذي تلانا كذلك؟ هل ينظرون لتجاربنا كما كنا ننظر لتجارب من سبقونا؟"( المحور الآخر: حضور المرأة / الشهادة الأدبية والتمرد - القلق الأيديولوجي يتصل هذا المحور بسابقه. حيث أن الساردات ومن خلال إبداعهن قد طرحن مجموعة من القضايا ذات صلة بعلاقة المرأة بمجتمعها وتقاليده وقيمه وأعرافه، وسياسته. خاصة ممن لم تستسلم ولم تؤمن أصلا بهيمنة الرجل وقدمت رؤيتها عبر إبداعها الأدبي. تشير لهذا الناقدة نورة الشملان بقولها: " إن سقف

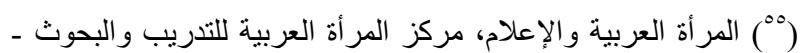

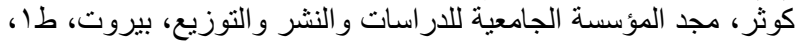

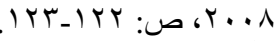

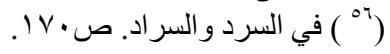


امتعضت بعض الناقدات السعوديات اللاتي بهتن من موجة التكرار والنمطية الواحدة التي سارت عليها الرواية النسائية تجاه وصم الرجل دوما بالقسوة والتسلط أو استجلاب الرومنسية الفجة. حيث تتنقد الناقدة منى الغامدي عمل الروائية سالمة المواشي لني وإنتاجها المحصور كله في البكائيات والرومانسيات الساذجة. (ז'). وتصف زينب حفني بطل الرواية (الزوج) بالثيطان في روايتها (الثيطان يحب أحيانا

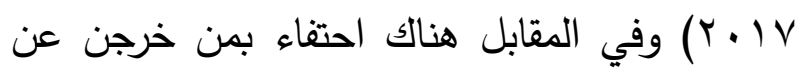
المسار الجمعي في الكتابة عن محيط الرجل. يتجلى لهن هذا في ثناء الناقدة نورة القحطاني لرواية جاهلية حيث تُحبّر قائلة: " تعالج الكاتبة هنا حالات نتات اجتماعية حساسة في رواية متميزة ومدروسة بعناية دون اللجوء إلى الفضائحية المنفرة أوالنياحة الأنثوية البائسة"( آل). وما أريد أن أقوله إن خوض غمار الثهادة كان

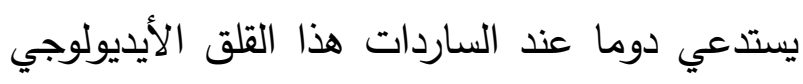
من فكرة التصنيف إلى ذكر وأنثى، وما يستتبع هذا

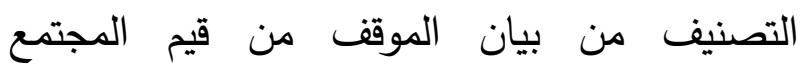
وتطلعات المرأة. وإن كان هذا التصنيف ربما يندثر

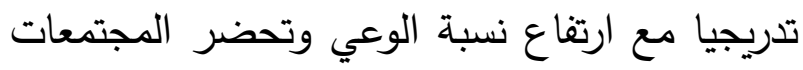

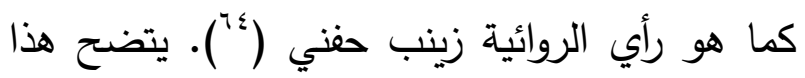

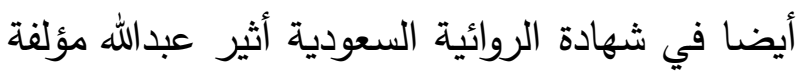
رواية أحبيتك أكثر مما ينبغي، عندما سئلت عن الرواتئ

(r) آلرواية وتحو لات الحياة في المملكة العربية السعودية، ص: 101.

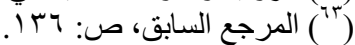

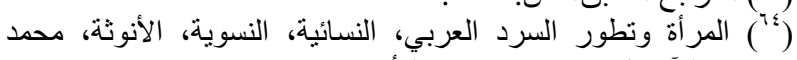

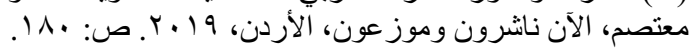

يمكن أن نشير إلى رواية بنات الرياض وما حققته من شهرة واسعة، واهتمام كبير، وفي الوقت نفسه

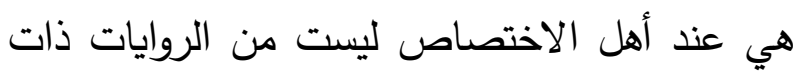

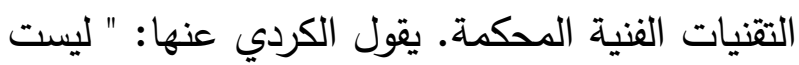
رواية حقيقية فنية، بل يمكن إدراجها فيما يسمى بشبه البهابه

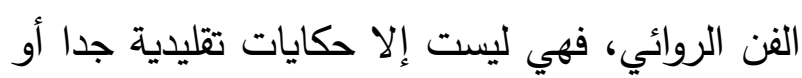

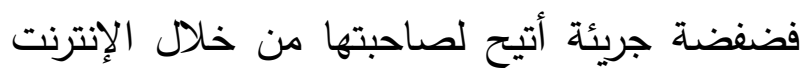

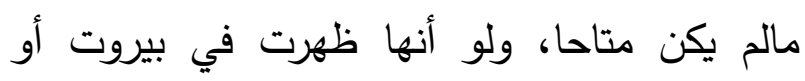

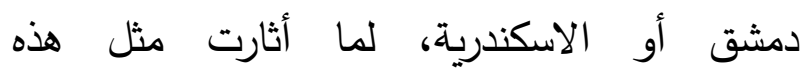

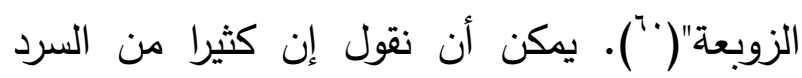

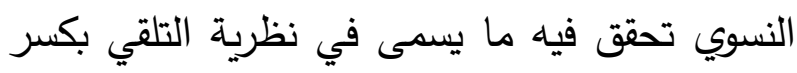

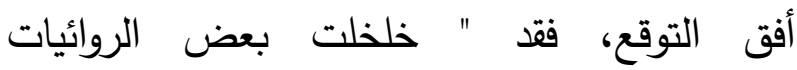
السعوديات أفق الانتظار من جوانب عدة، من بينها

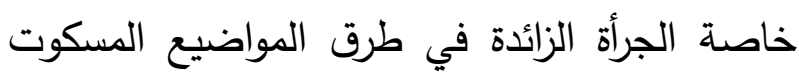

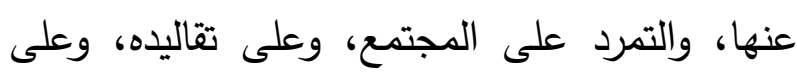
عقليته العامة، وغير ذلك من الجوانب التي أثارت القراء في تعاملهم مع هذه المدونة النسائية "("). التي ساقت بعض الأعمال الرجالية أن تركب موجتها لغداه

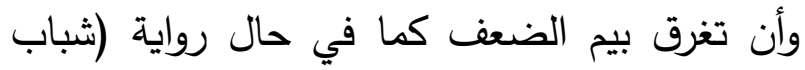

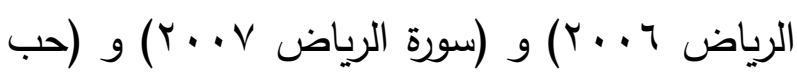

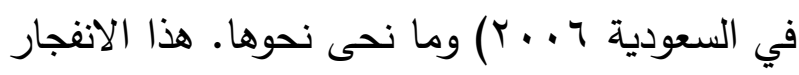
السردي الروائي النسائي وما حواه من مضمون متثابه مع بداية ظهور التقنيات الرقمية الحديثة لم

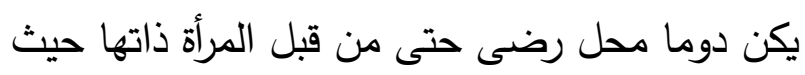

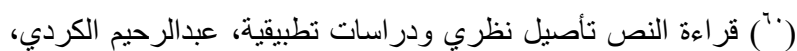

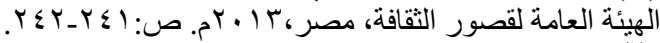

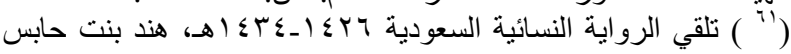

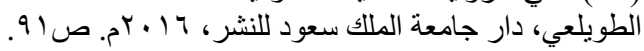


1- أن الشهادة الأدبية لون من ألوان تفسير النص

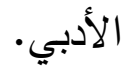

r- مسألة تجنيس الشهادة الأدبية بوصفها لونا أدبيا قائما بذاته مسألة تعوزها الدقة، لأن ماهية

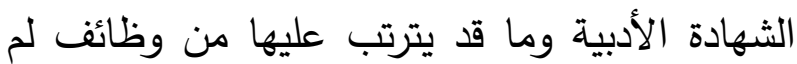
تتضح أو تتكثف بشكل كاف.

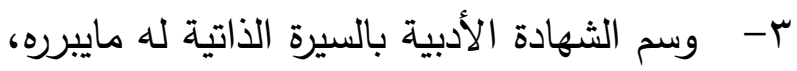
لكن الراني يدرك في الوقت نفسه أن الفروق بينهما كبيرة جدا. ع - بناء صورة الذات هي الفكرة المحورية التي تلتقي فيها الثهادة الأدبية والسيرة الذاتية.

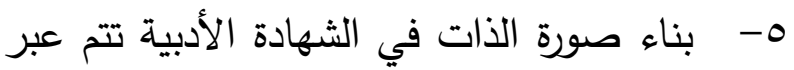
عملية وعي ونقطة التقاء بين الذات الفردية والذات

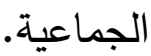
؟- وقَََتْت المرأة السعودية الساردة في شهادتها على القضايا الكبرى في المجتمع، وأظهرت مكنون بعض الزوايا التي غفل عنها الرجل. V- رصدت الساردات السعوديات في شهاداتهن أن أفق التوقع السلبي في مواقف المجتمع من مناقشة الساردات لقضايا تتعلق بالمرأة جعلهن يلجأن إلى لعبة الأسماء المستعارة.

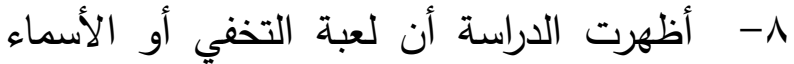
المستعارة للساردات السعوديات لم تكن بواعثها وأهدافها واحدة ولذا صارت ظاهرت عالمية، تتعدد

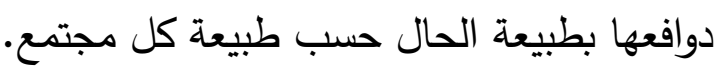

تشابه بعض شخصياتها النسائية مع رواية بنات الرياض، ومفهوم قوة المرأة في روايتها، وكانت إجابتها: أن شخصيتها غرست في مجتمع يعتمد كلية على الرجل في تسيير نظام الحياة بما يوافق هواه (") ) وحين ترتكز الكاتبة على أرض واقعها فستجد ما آمنت به سمة مسلم بها عند البعض أيضا حيث ترنكر البه

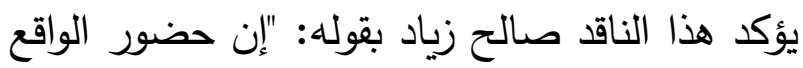
في قراءة الرواية السعودية يبدو طاغيا ومهيمنا"(7"7). بينما تؤكد زينب حفني أن الأدب النسائي السعودي لروائ أدبا ثوريا بامتياز، أثره في تغيير المجتمع يفوق أثر الثردي

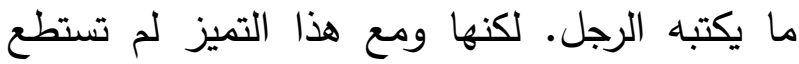
كتابة السيرة الذاتية التي تحتاج لامتلاك جرأة واسعة لهانة

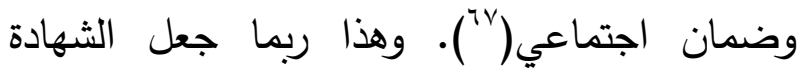
الأدبية لدى قلم الكاتبة يعتريه شيء من الضعف

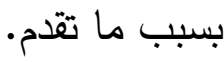
وتحرص شريفة الشملان في شهادتها أن تبين الفوارق بين كتابة السرد وكتابة الدقال، فالأول قد يمكن المرو من التخلص من القلق الإيديولوجي المصنف للمرأة بعكس المقال الذي يكثف كامل الوعي ويخضع للمساءلة الرقابية (^^). الخاتمة

توصل البحث في ضوء فروضه النظرية وما قدمه من نماذج تطبيقية إلى عدد من النتائج التي لمسها القارئ الكريم بتفاصيلها مما سبق والتي من أبرزها:

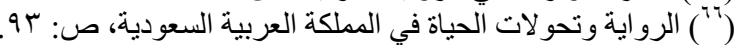

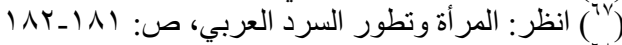

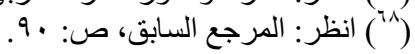


بلاغة الشهادة الإبداعية نحو تأسيس لجنس أدبي جديد، أيمن تعيلب، دار العلم والإيمان، كفر الشيخ، $.5+10$ التحولات في الرواية العربية، نزيه أبو نضال، المؤسسة العربية للدراسات والنشر ، بيروت، ج ج . ب م.

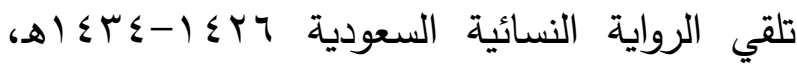
هند بنت حابس الطويلعي، دار جامعة الملك سعود

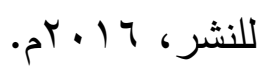

تمظهرات الشكل السير ذاتي قراءة في تجربة محمد القيسي السير الذاتية، محمد صابر عبيد، منشورات اتحاد الكتاب العرب، دمشق، 0. . بام.

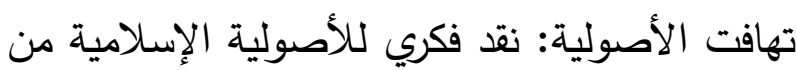
خلال واقعها المعاش، شاكر النابلسي، المؤسسة العربية للدراسات والنشر ، 9 . . بم. حوارات في الرواية العربية، طامي محمد السميري،

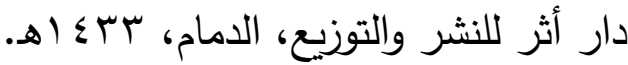
حياة الكتابة، مقالات مترجمة عن الكتابة، إعداد

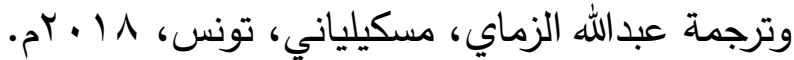

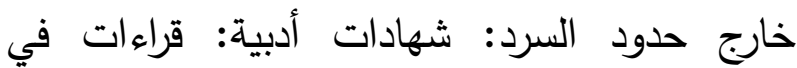
المشهد الإبداعي وحوارات، إبراهيم درغوثي، دار

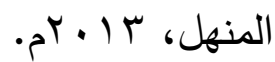
دردشة حوارات معلنة، إعداد وترجمة أمل فارس، دار مددوح عدوان للنشر والتوزيع، سوريا، 1 ا • بَ. الذات الثاعرة والقبيلة بوصفها مؤسسة اجتماعية،

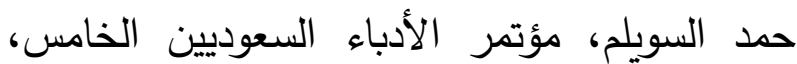

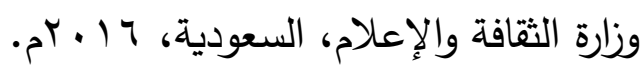

9- - ظهر من خلال ماسبق أن لعبة التخفي أو الأسماء المستعارة اختفت أو كادت.. مع التحولات المجتمعية الحديثة، وتعزيز دور المرأة في المجتمع. • 1- الشهادات الأدبية عبرت عن القلق الأيدلوجي الذي تشعر به الساردات السعوديات. هذا والله أعلم، وصلى الله على نبينا محمد. المصادر والمراجع

أبحاث ملتقى القصة القصيرة والقصة القصيرة جدا في الأدب السعودي - الذات والطريق الحلم حكيمة الحربي، تحرير صالح معيض الغامدي و حسين المناصرة، كرسي الأدب السعودي، جامعة الملك سعود، الرياض، ع بـ اهـ. الأسماء المستعارة عند الأدباء في المملكة العربية السعودية دراسةٌ في دلالات المضامين والألنية، إبراهيم المطوع، مجلة كتابات، إصدار خاص، دلان الجمعية المصرية للدراسات السردية، أكتوبر - نوفمبر إصندات

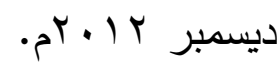
آليات السردية المقاومة في النص السير ذاتي النسوي - شهادة الكاتبة العربية نموذجا، أحمد عبدالقادر الحسيني، المؤتمر الدولي الثالث للدراسات

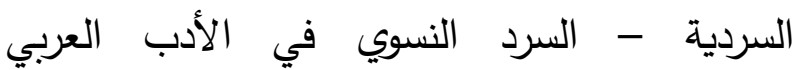

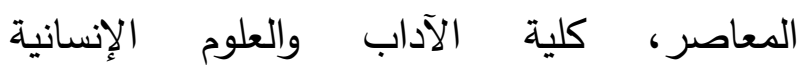
بالإسماعيلية بالاشتراك مع الجمعية المصرية

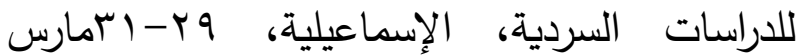
.$p^{r} \cdot 1 \cdot$ 
الشهادة الأدبية والتجربة الإبداعية:عبد الرحمن مجيد الربيعي أنموذجا، مولود مرعي حسن، المنهل، . . $^{-1}$. I

في الأطر النظرية للتلقي: مدارات القراءة تفسير القراءة من مداخل العلوم الإنسانية، محمد مريني، دار كنوز المعرفة، الأردن، 10 • بـ. من.

في بلاغة الحجاج نحو مقاربة بلاغية حجاجية

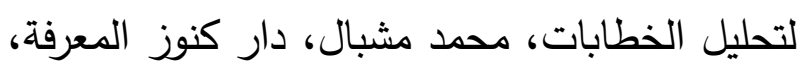

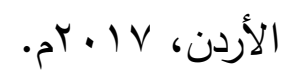

في حضرة الغياب، محمود درويش، دار رياض

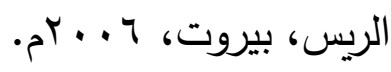

قراءة النص تأصيل نظري ودراسات تطبيقية، عبدالرحيم الكردي، الهيئة العامة لقصور الثقافة،

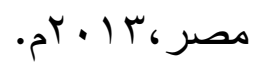

القصة القصيرة السعودية، شهادات ونصوص، في السرد والسراد، شهادة ليلى الأحيدب، جمع وإعداد خالد اليوسف، كرسي الأدب السعودي، جامعة الملك لك

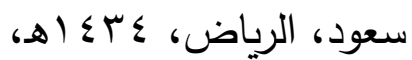
الكتابة والمتخيل، المهجرية الجديدة، الأدب النسوي،

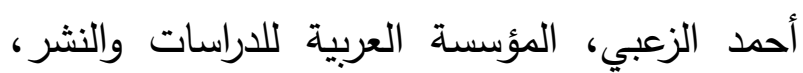
بيروت، 9191 ام. المرأة العربية والإعلام، مركز المرأة العربية للتدريب والبحوث -كوثر، مجد المؤسسة الجامعية للدراسات والنشر والتوزيع، بيروت، طال، 1 . . rم.

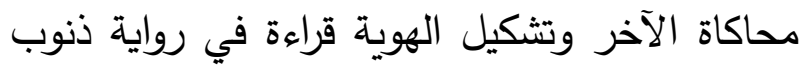
جميلة، شكري الطوانسي، أبحاث المؤتمر الدولي
الرواية وتحولات الحياة في المملكة العربية السعودية، ملتقى الباحة الثقافي الثاني، مجموعة كتاب، وزارة

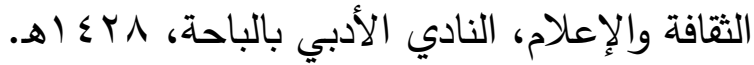
السرد التاريخي عند بول ريكور، جنات بلخن،

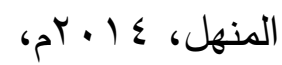
سلسلة أبحاث المؤتمرات Vا، ال، ملتقى القاهرة الثاني للإبداع الروائي العربي، الرواية والمدينة، دورة إداوارد

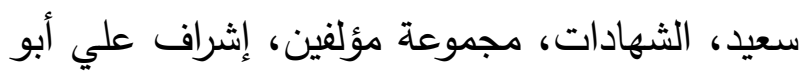

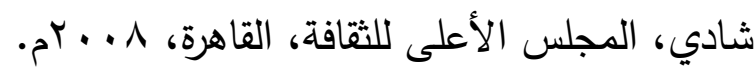
السيرة الذاتية المقاومة - الأنواع الأدبية الخارجة الأهلية على القانون والذوات النسوية عبر القومية. مقال ضمن كتاب: النقد الأدبي النسوي، ترجمة وتقديم هالة كمال، مؤسسة المرأة والذاكرة، سلسلة ترجمات نسوية ه، القاهرة، 0 • • بم. السيرة الذاتية في الأدب السعودي دراسات نقدية، تحرير صالح معيض الغامدي، عبدالله الحيدري، كرسي الأدب السعودي، جامعة الملك سعود، معيط، الرياض، ع ع أهـ السيرة الذاتية مقاربة الحد والمفهوم، أحمد علي آل آل مريع، سلسلة كتاب المجلة العربية رقم ل IVA

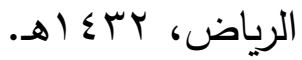
الثهادات الأدبية في السعودية: مقاربة سوسيو أدبية، محد الصفراني الجهني، مجلة علامات في النقد

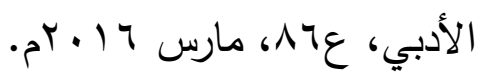


المقالة النسائية السعودية، دراسة أسلوبية، أمية

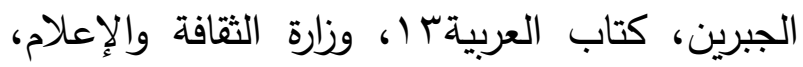

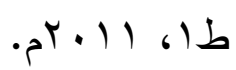

من الإنشائية إلى الدراسة الأجناسية، أحمد الجوة،

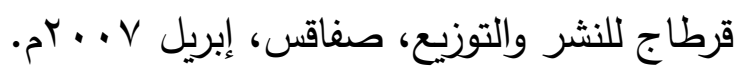
النظرية الأدبية المعاصرة، رامان سلدن، ترجمة جابر

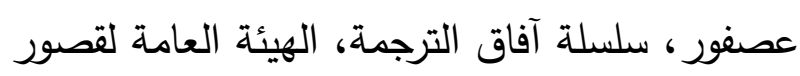

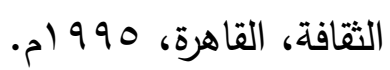
نظرية السيرة الذاتية (المصطلح، الأنواع، الحقيقة النقانة والخيال )، أحمد علي آل مريع، ضمن السيرة الذاتية

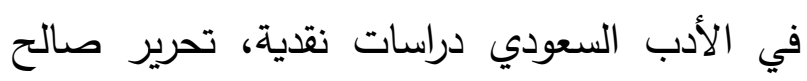
معيض الغامدي و عبدالله الحيدري، كرسي الأدب

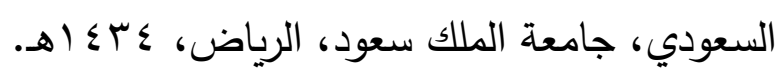
نقد السرد السير ذاتي والقصصي والروائي: دراسة في الخطاب النقدي لـحمد صابر عبيد، نبهان ولنيان

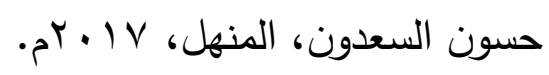

Alfauzan Abdullah H A, 2013. The City and Social Transformations in Arabic Literature: The Saudi Novel as Case Study $(Y \cdot 11-191 \cdot)$ for the degree of Doctor of Philosophy, University of Leeds.

Elamin, A. M. O. Katlin 2010. "Males' Attitudes towards Working Females in Saudi
الخامس للدراسات السردية، الجمعية المصرية للدراسات السردية بالاشتراك مع مركز اللغة العربية

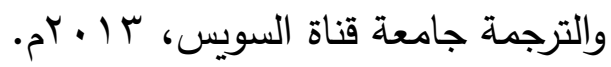

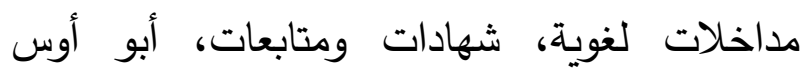

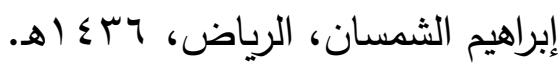

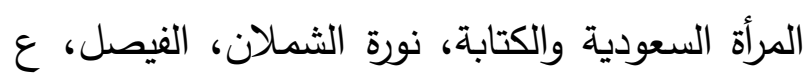

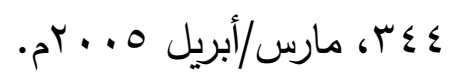
المرأة وتطور السرد العربي، النسائية، النسوية، النائ، الأنوثة، محمد معتصم، الآن ناشرون وموزعون،

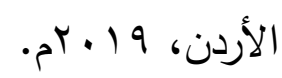

مرايا التذوق الأدبي: دراسات وشهادات، خليل

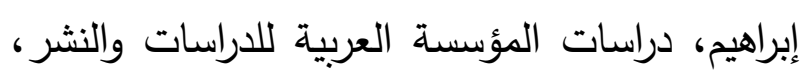

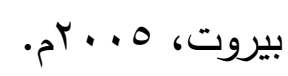
معجم السرديات، إشراف محمد القاضي، الرابطة

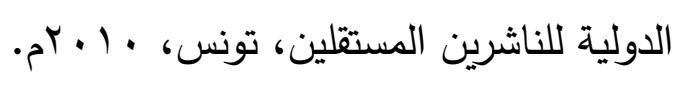

Arabia". Business and EconomicsManagement.

IRENA R. Makaryk, 1995. Encyclopedia of Contemporary Literary Theory, Approaches, Scholars, Terms. University of Toronto Press, Canada. 


\title{
Literary Recognition and Self-image Construction: Saudi Women Writers as an Example
}

\author{
Abdullah H. Alfauzan. \\ College of Arabic \& Social Studies, \\ Arabic department. Qassim University,
}

\begin{abstract}
Literary prose is one of the prevailing and widespread genre that writers and literary men deliberated on these days. Thus, literary appreciation, as an example, is looked upon as a remarkable link between readers and writers. In fact, it is considered an avenue of analyzing and revealing the secrets of the literary text, especially from the point of view of the creator, who seeks to reach his/her goal entirely to the reader's world. At this point, selfimage is reflected in these appreciations that can be explained and interpreted via various approaches. In the first approach, the creator provides a typical picture of the self-image during work and after attending the conference. The second point involves when the female writer monitors the self and sees its interaction with the outside world. Actually, both approaches are methods for reading the literary text. The narrative approach of Saudi women is an important and vital milestone in the history of Arabic literature because it recently captivates the attention of many popular critics, publishing houses, translators and the media

Therefore, the study discusses the nature of the Saudi female narratives from the perspective literary appreciation which leads us to answer the following questions such as:

1. How does literary recognition build the image of the self and how it is related to the biography of the writer?

2. How did Saudi women writers monitor the relationship between the text and community issues at the level of literary recognitions?

3. Is there a significant difference between what Saudi women have recorded in the literary recognitions and what is in the literary text?

This research methodology will focus on the idea that literary recognition is an approach which considers the importance of the explanatory achievements of Saudi women writers and how the community received these explanations, presented in the creative text.
\end{abstract}

